ORNL/TM-2000/116

\title{
COMPARISON OF PRIME MOVERS SUITABLE FOR USMC EXPEDITIONARY POWER SOURCES
}

\author{
T. J. Theiss \\ J. C. Conklin \\ J. F. Thomas \\ T. R. Armstrong * \\ * ORNL Metals \& Ceramics Division (M\&C)
}

March 2000 
Engineering Technology Division

\title{
COMPARISON OF PRIME MOVERS SUITABLE FOR USMC EXPEDITIONARY POWER SOURCES
}

\author{
T. J. Theiss \\ J. C. Conklin \\ J. F. Thomas \\ T. R. Armstrong * \\ * ORNL Metals \& Ceramics Division (M\&C)
}

Manuscript completed: March 2000

Date published: March 2000

\author{
Prepared by \\ Oak Ridge National Laboratory (ORNL) \\ Oak Ridge, TN 37831-8088 \\ Managed by \\ LOCKHEED MARTIN ENERGY RESEARCH, INC. \\ for the \\ U. S. DEPARTMENT OF ENERGY \\ under contract DE-AC05-96OR22464
}





\section{CONTENTS}

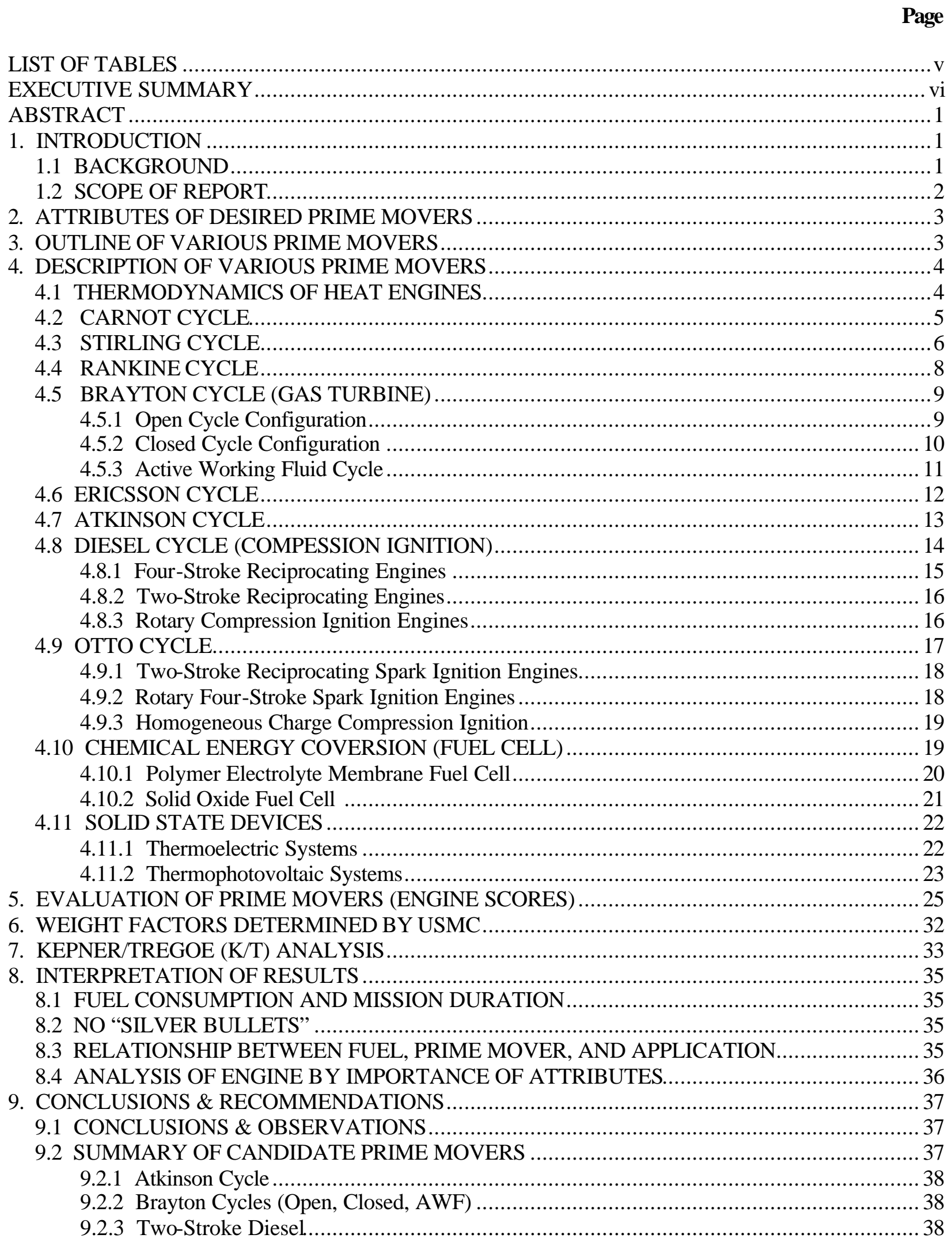




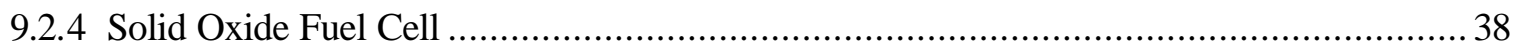

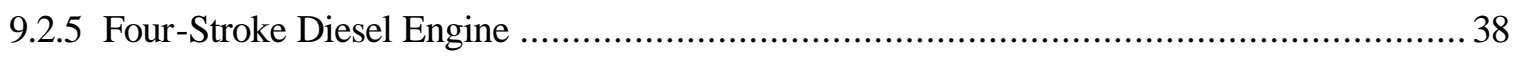

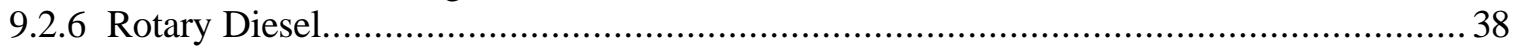

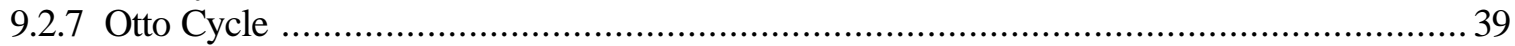

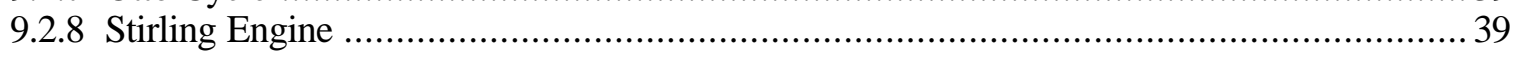

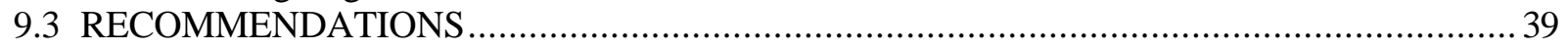

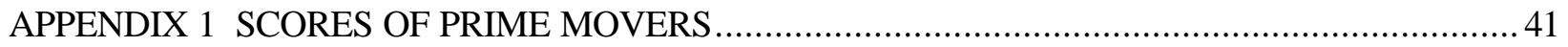

APPENDIX 2 FINAL WEIGHTED SCORES OF PRIME MOVERS .......................................... 57 


\section{LIST OF TABLES}

Table

Page

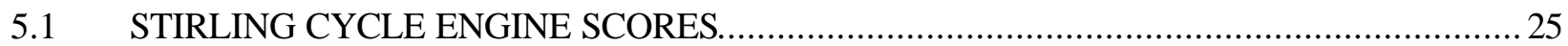

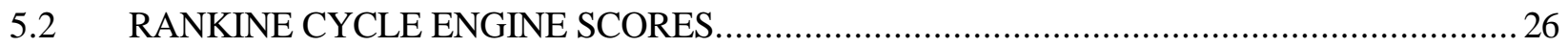

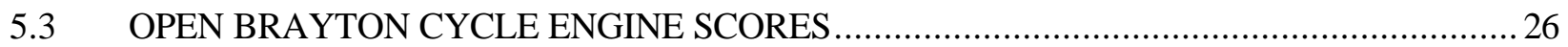

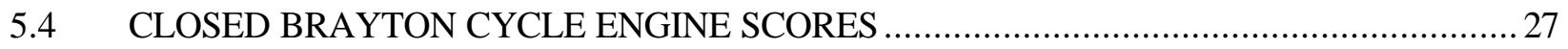

5.5 ACTIVE WORKING FLUID CYCLE ENGINE SCORES..........................................2 27

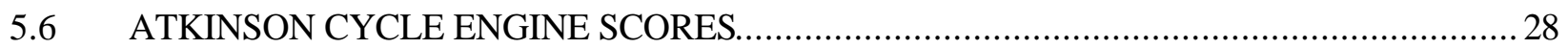

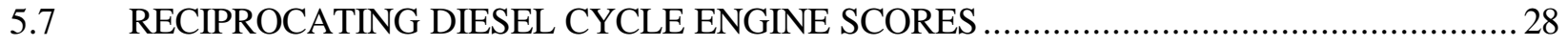

5.8 TWO-STROKE RECIPROCATING DIESEL ENGINE SCORES..................................29

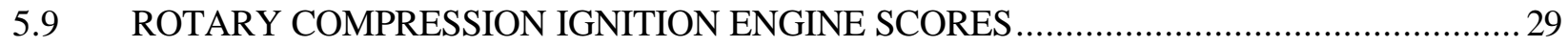

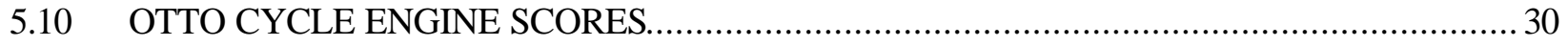

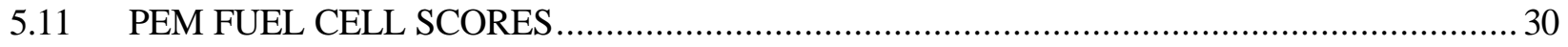

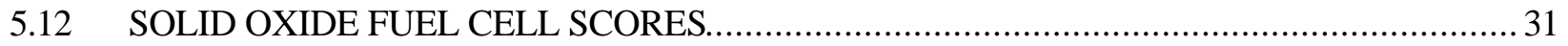

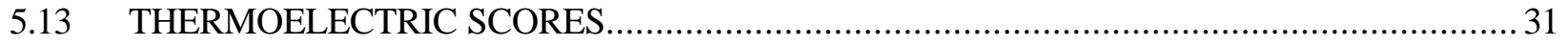

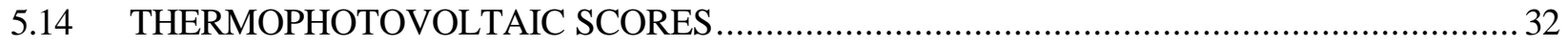

$6.1 \quad$ USMC WEIGHT FACTROS FOR ENGINE ATTRIBUTES …..................................... 32

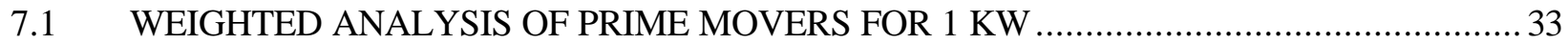

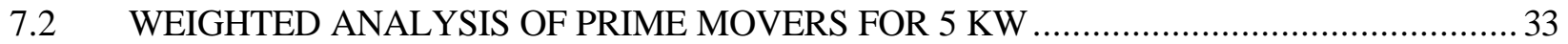

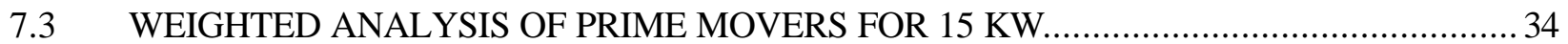

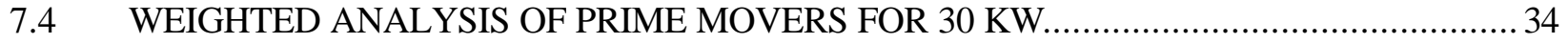

8.1 WEIGHTED ANALYSIS BY IMPORTANCE LEVEL FOR 5 KW ............................... 36 


\section{EXECUTIVE SUMMARY}

This report documents the results of the ORNL investigation into prime movers that would be desirable for the construction of a power system suitable for the United States Marine Corps (USMC) expeditionary forces under Operational Maneuvers From The Sea (OMFTS) doctrine. The conclusions of this effort and the recommendations on future prime movers for USMC expeditionary forces are given herein. Additional details supporting this summary and details on multiple prime movers are given in the main body of the report.

\section{Conclusions \& Observations}

- The time frame for deployment of OMFTS (2010) will force the selection of a relatively mature prime mover or the rapid development of less mature technologies. Research to find new choices not yet "on the scene" appears unlikely to produce a suitable unit in sufficient time.

- The scalability of the prime movers varies widely and is a major driver behind the differing recommendations between the higher and lower load levels.

- No single prime mover exists that is clearly superior in all (or even most) areas (i.e., no "silver bullet" exists).

- The relationship between the fuel, prime mover, and application is intertwined and must be understood. If the fuel or applications changes, the most suitable prime mover likely will be different as well.

- The expeditionary forces represent a unique application for gen-sets, which must be treated uniquely.

- The importance of fuel economy needs to be reconsidered. Mission durations of two weeks are possible, which would have high fuel re-supply requirements if inefficient engines were used.

- The goal of developing a unit capable of $5 \mathrm{~kW}$ that weighs less than $150 \mathrm{lb}$ is clearly ambitious but can be achieved with some risks. Tradeoffs will certainly have to be made.

\section{Recommendations}

- This is a vital area that will require continued USMC attention. We recommend that the USMC further refine their needs and desires for generator sets for expeditionary forces.

- For larger sizes, we recommend that the USMC monitor the market on the commercial and military sides to determine if suitable generator sets will be available. In our opinion, it is highly likely that suitable (not perfect) gen-sets at this size range will be available in the 2010 timeframe without significant intervention (funding) from the USMC.

- The open Brayton cycles (gas turbine) are the best choice for the larger sizes if the diesel gen-sets being developed at DOD are not appropriate. Commercial products should be evaluated for their suitability. The open cycles should be developed first. If improved fuel economy becomes necessary, the closed Brayton cycle will be more attractive but the maturity level between the open and closed Brayton is large. 
- USMC resources should be focussed on the smaller sizes $(1 \& 5 \mathrm{~kW})$ where the needs are greater and the risks must be minimized.

- The initial focus of any development should be on the areas of most importance (weight, volume, etc.). In other words, develop a small light engine first, then make it better by making it more efficient or quieter, etc.

- We recommend that for $1 \& 5 \mathrm{~kW}$, multiple options be pursued to minimize the risk and hopefully provide an optimum solution. We feel the best candidates are the Atkinson, Brayton (turbine), and 2stroke diesel cycles. Backup choices would be the rotary diesel and the SOFC.

- The backup choices should be watched to determine if they might overcome the shortfalls described in this report. UAV engine developments should be tracked for improvements in this technology.

- The Atkinson cycle is our recommendation as the most suitable engine to pursue even though it is the least mature of the three. Currently ORNL is working with the inventor to perform proof-of-principle tests for this engine, which should take several months to complete (October 2000). Pending a successful outcome, the overall suitability will be better known.

- The primary candidate engines (Atkinson, turbine, and 2-stroke diesel) should be further investigated and evaluated to identify the potential barriers of each and estimate the overall performance of a genset using each engine. Simulation packages at ORNL can be useful in this effort.

- Once the overall performance is estimated, the risks and costs associated with each engine can be determined and the decision to develop one or more potential solutions should be made.

It is our intent that this report will be used by the USMC to develop an engine that is suitable for expeditionary force gen-sets. This is a technically challenging area that will require attention from the USMC for the near future. 


\title{
COMPARISON OF PRIME MOVERS FOR USMC EXPEDITIONARY POWER SOURCES
}

\author{
T. J. Theiss, J. C. Conklin, J. F. Thomas \& T. R. Armstrong
}

\begin{abstract}
This report documents the results of the ORNL investigation into prime movers that would be desirable for the construction of a power system suitable for the United States Marine Corps (USMC) expeditionary forces under Operational Maneuvers From The Sea (OMFTS) doctrine. Discrete power levels of $\sim 1,5$, 15 , and $30 \mathrm{~kW}$ are considered. The only requirement is that the prime mover consumes diesel fuel. A brief description is given for the prime movers to describe their basic scientific foundations and relative advantages and disadvantages. A list of key attributes developed by ORNL has been weighted by the USMC to indicate the level of importance. A total of 14 different prime movers were scored by ORNL personnel in four size ranges $(1,5,15, \& 30 \mathrm{~kW})$ for their relative strength in each attribute area. The resulting weighted analysis was used to indicate which prime movers are likely to be suitable for USMC needs. No single engine or prime mover emerged as the clear-cut favorite but several engines scored as well or better than the diesel engine. At the higher load levels $(15 \& 30 \mathrm{~kW})$, the results indicate that the open Brayton (gas turbine) is a relatively mature technology and likely a suitable choice to meet USMC needs. At the lower power levels, the situation is more difficult and the market alone is not likely to provide an optimum solution in the time frame desired (2010). Several prime movers should be considered for future developments and may be satisfactory; specifically, the Atkinson cycle, the open Brayton cycle (gas turbine), the 2-stroke diesel. The rotary diesel and the solid oxide fuel cell should be backup candidates. Of all these prime movers, the Atkinson cycle may well be the most suitable for this application but is an immature technology. Additional demonstrations of this engine will be conducted at ORNL. If this analysis is positive, then the performance of a generator set using this engine, the open Brayton and the 2-stroke diesel should be estimated to evaluate its potential suitability for expeditionary forces. The overriding conclusion of this effort is that we feel a suitable prime mover can be found but that the development will be technically challenging and trade-offs will be made before an optimum solution is found.
\end{abstract}

\subsection{INTRODUCTION}

This report documents a portion of the work conducted for the United States Marine Corps (USMC) Warfighting Laboratory by personnel at the Department of Energy (DOE) Oak Ridge National Laboratory (ORNL). The project, entitled "Specialized Auxiliary Power Unit for Sea-Based Logistics" (DOE No. 2252-AA12-Y1, USMC No. M9545099MRR9AWM) was carried out from April 1999 until the issuance of this report.

\subsection{Background}

The Marine Corps concept, Operational Maneuvers From The Sea (OMFTS), will require implementation of new amphibious warfare concepts and capabilities. OMFTS emphasizes using the sea as a secure area from which to conduct ship-to-objective movement. Naval forces will provide enhanced naval fires, force protection, command and control, surveillance and reconnaissance, and logistics support for Marines ashore -- enabling the high-tempo operations envisioned by OMFTS. OMFTS will require logistics innovation to enhance strategic sealift and sea-borne capabilities. 
A specific area of USMC concern is the requirement for mobile power systems, which are essential and ubiquitous for military operations in urban littorak. The USMC and Marine Corps Warfighting Laboratory (MCWL) are concerned that the two big obstacles - bulk fuels and mobile electrical generator sets (gen-sets) - will make it impossible to sea-base combat service support (CSS) as planned for in OMFTS doctrine unless significant power density improvements are achieved.

Significant improvements can be made in the total weight and volume of the gen-set by focussing on system optimization. However to meet the demands of OMFTS additional size and weight reductions are necessary which forces additional attention on the prime mover (in most cases an internal combustion diesel engine). ORNL has embarked on a detailed, directed study to determine the most promising, high payoff technologies that can be incorporated into a prime mover of a power system uniquely designed for the highly mobile, specialized, sea-based applications required by OMFTS. The goal is to provide an objective assessment of the various engine types available, which will prevent promising technical options from being overlooked while providing a basis for analyzing and selecting the optimum prime mover for the USMC.

\subsection{Scope of Report}

This report documents the results of the ORNL initial investigation into prime movers that would be desirable for the construction of a power system suitable for the USMC expeditionary forces under OMFTS doctrine. The report includes the following information culminating in a series of recommendations that provide guidance in selecting the optimum prime mover for the desired power systems. Discrete power levels of $\sim 1,5,15$, and $30 \mathrm{~kW}$ are considered.

- Key attributes deemed important for USMC expeditionary power requirements are listed and briefly explained. The USMC has reviewed and approved these attributes to assure that the resulting prime mover satisfies USMC power requirements.

- A listing and brief description of the processes that can convert readily available fossil fuel (in this case, diesel fuel) into mechanical and/or electrical energy will be provided. The engine associated with each of these processes will be included. While the scientific basis for prime movers (i.e., the thermodynamics) has not and will not vary dramatically over time, the engines, which are constructed, do change quite a bit throughout time. Therefore it is important to understand the scientific underpinnings of these engines to assess where future improvements are likely.

- The performance of each engine is then described paying particular attention to evaluate the performance of the engine against the attributes of interest. Since many of the attributes are subjective, part of this evaluation is narrative. Care has been given to assure that each prime mover is evaluated on a "level playing field" in an unbiased manner. To provide a quantitative comparison, ORNL has also evaluated each engine for its relative strength in each attribute area and assigned a value. A numbering system of values from 1-10 is used and is included in this report.

- All attributes were evaluated and assigned a weighting factor by the USMC for their relative importance for expeditionary gen-sets. A numbering system of values from 1-10 was used.

- The engine evaluation values and the attribute weighting factors are used with the Kepner/Tregoe technique to compare the engines at each power level. The resulting analysis is used to select the optimum prime mover among the various options.

Once the most promising technologies have been reviewed and scored, recommendations are made for developing a highly mobile, specialized power system, which can be used for supporting expeditionary forces consistent with OMFTS. The USMC has expressed a need for a generator set that can produce 5 
$\mathrm{kW}$ of power and weigh less than $150 \mathrm{lb}$. Prime movers most likely to meet this ambitious goal are described.

\subsection{ATTRIBUTES OF DESIRED PRIME MOVERS}

The following attributes (as opposed to "requirements") are important to consider in designing a power system suitable for expeditionary applications. The attributes described here are specifically related to the prime mover used in a power system. The primary assumption is that diesel fuel is used and that any necessary modifications or additional equipment to use diesel fuel has been considered when evaluating the attributes of each engine. Comments will be provided in the following sections to relate the prime movers described here to the overall power system.

USMC List of Desirable Attributes (diesel fuel consumption is assumed):

- High efficiency (low fuel consumption)

- Low weight

- Low volume

- Low acoustic signature

- Low electromagnetic (EM) signature

- Low Infrared (IR) signature

- Technical maturity (or risk) (how uncertain is the technology?)

- Low cost (manufacturing and operating)

- Load following or partial load operation

- Low emissions (if the USMC is not looking at this, the trend is that they will be)

- Easy to use (does it take a PhD or full-time mechanic to keep it running?)

- High ruggedness/durability (is it fragile, quirky, will it withstand the abuse it will likely receive?)

- Low maintenance requirements

- High Reliability (when it is turned on - it must work. Ultimately reliability is a function of the mission duration that will need to be determined.)

\subsection{OUTLINE OF VARIOUS PRIME MOVERS}

The following outline of prime movers is as near comprehensive as possible. The list is intended to be inclusive so as not to overlook any reasonable possibility. Certain academic prime movers were omitted due to their impracticality. In order to be comprehensive, we have considered prime movers in addition to heat engines, specifically the fuel cell and solid-state devices.

The initial listing is based on scientific foundations to provide a comparison that will not be outdated in a short time period. This approach is intended to help evaluate existing options and future alternatives that are not readily available. In other words, the science, which governs engine operation, has not and will not change much in the next few decades. The engines themselves that are seen in the market certainly will change. Many claims for a better engine have not stood the test of scientific scrutiny, time, or economics. This approach should provide a level playing field for engines available today while providing insight into the engines that might be available in the future and could be considered. 
I. Combustion Cycles (Heat engines)
A. Carnot
B. Stirling
C. Rankine
D. Brayton

1. Open (gas turbine)

2. Closed

(i). Inert working fluid

E. Ericsson

(ii). Active working fluid

F. Atkinson

G. Diesel (compression ignition)

1. Reciprocating

(i). 4-stroke cycle

(ii). 2-stroke cycle

2. Rotary

H. Otto (spark ignition)

1. Reciprocating ("gas" engine)

(i). 4-stroke cycle

(ii). 2-stroke cycle

2. Rotary

II. Chemical (Fuel cells)

3. Homogeneous Charge Compression Ignition (HCCI)

A. Proton Exchange Membrane Fuel Cells (PEMFC)

B. Solid Oxide Fuel Cells (SOFC)

III. Solid State
A. Thermovoltaics (TVs)
B. Thermophotovoltaics (TPVs)

\subsection{DESCRIPTION OF VARIOUS PRIME MOVERS}

This section describes the various prime movers just outlined. A brief theoretical discussion of heat engines is in the next section; followed by a description the various cycles or engines that could be considered and their general performance. The scientific concepts, which underpin the fuel cell and solidstate devices, are in subsequent sections followed by a description of their general performance.

\subsection{Thermodynamics of Heat Engines}

All heat engines operate with four basic processes: pumping or compression, heat addition, expansion, and heat rejection. These basic processes may be carried out by the various cycles in various manners, but the basic processes are common to all. These processes are either performed by or to a fluid that flows inside the engine and is thus called the "working fluid." If any process occurs at a constant temperature, that process is isothermal. If the compression or expansion process occurs without heat transfer, that process is adiabatic. Adiabatic processes occur during rapid expansion or compression when the time scale for pressure change is much faster than the time scale for heat transfer. All heat engines operate between a high and a low pressure $\left(\mathrm{P}_{h}\right.$ and $\left.\mathrm{P}_{1}\right)$ and between a high and a low temperature $\left(\mathrm{T}_{\mathrm{h}}\right.$ and $\left.\mathrm{T}_{1}\right)$ measured on an absolute scale. The thermal efficiency of the various heat engines is of interest, because it represents a ratio of the desired work output and the required heat input. Power density is also of interest since the size of the prime mover is so important to the USMC. 
Different inventors have combined and coupled the four processes of a heat engine into various thermodynamic cycles that usually bear their names. Some of the more practical cycles are described in the following sections. Attention is given to the differences between theoretical or ideal and practical limits of these prime movers. For example, the friction present in all moving parts will always decrease efficiency. Some of the aspects of the thermodynamic process may be only approximated in practical machinery. As a result, the cycle with the higher ideal efficiency may not have the higher practical efficiency in an operating machine.

The cycles can be described as "intermittent" where the processes occur in a periodic fashion (such as the diesel engine), or "continuous" having constant process characteristics (such as the gas turbine). Because of material temperature limitations, intermittent machines tend to have a high thermal efficiency than continuous machines. Because of fluid flow considerations, however, continuous machines tend to have a higher power output per unit volume than intermittent machines. Thus, the choice of any particular heat engine is often a compromise between efficiency and power density.

All heat engines must obey the First and Second Laws of Thermodynamics. The First Law states that energy is conserved in any process and since heat and shaft work are equivalent forms of energy, the heat flows and the work must be equal. The Second Law can be simply stated that the thermal efficiency of any heat engine cannot be greater than the thermal efficiency of an ideal cycle (known as the Carnot cycle). If any proposed heat engine has efficiency greater than Carnot, it must be a perpetual motion machine and thus impossible.

The following cycles represent the vast majority of heat engines, which might be used as the prime mover in an expeditionary power source.

\subsection{Carnot Cycle}

The Carnot cycle is introduced only to show the fundamental efficiency limitations of heat engines. This ideal cycle was devised and represents the upper limit possible for the efficiency of converting heat to work. Thus, if the efficiency of any engine is claimed as greater than Carnot, it is immediately suspect or it is not a heat engine.

The Carnot cycle begins with an adiabatic compression, then isothermal heat addition at $\mathrm{T}_{\mathrm{h}}$ having a heat flow of $\mathrm{Q}_{\mathrm{h}}$, adiabatic expansion, then isothermal heat rejection at $\mathrm{T}_{1}$ with a heat flow of $\mathrm{Q}_{1}$ to begin the cycle again.

From the First Law of Thermodynamics, the work obtained is the difference between the heat added and the heat rejected. It can be shown that the heat flow in this cycle is directly proportional to the temperature. So the Carnot thermal efficiency is defined as:

$$
\eta=\frac{W}{Q_{h}}=\frac{Q_{h}-Q_{l}}{Q_{h}}=1-\frac{T_{l}}{T_{h}}
$$

Note that no parameters specific to the working fluid appear, so this thermal efficiency expression is independent of the working fluid. No ideal Carnot engines exist because of the impracticality of realizing these processes sequentially, not to mention the losses due to friction. But this ideal machine does offer insight into the importance of adding heat at a high temperature and rejecting heat at a low temperature in order to improve the thermal efficiency of any heat engine. Note that heat must both be added and rejected. A heat engine must be in thermal contact with both a heat source, usually combustion, and a heat 
sink, usually ambient conditions. In summary, the thermal efficiency increases as the temperature difference between the heat reservoirs increases.

\subsection{Stirling Cycle.}

The Stirling cycle starts with isothermal (constant temperature) compression of a vapor from $P_{l}$ to an intermediate pressure, heating at constant volume to $P_{h}$ and $T_{h}$, isothermal expansion to produce work from $P_{h}$ to an intermediate pressure, then cooling at constant volume to pressure $P_{l}$ and $T_{l}$ to complete the cycle. An interesting and significant advantage of the Stirling cycle is that under ideal conditions, the thermal efficiency is equal to the Carnot upper limit. The actual thermal efficiency of operating Stirling cycle machines is, of course, less than Carnot.

One major advantage of the Stirling cycle is that heat is added external to the working fluid, so any fuel can be used to generate the heat. This external heat addition can result in a smooth, quiet engine as compared to other competing cycles. A disadvantage resulting from this external heat addition is that the effective heat transfer rate is low (Simon and Seume, 1990). Another disadvantage is that the net output power is low unless the working-fluid pressure levels are raised. Since air is not a very good working fluid due to its low thermal conductivity, helium and hydrogen are preferred but still the pressure must be higher than atmospheric. Unfortunately, these light gases (hydrogen in particular) tend to leak at high pressure and temperature, thus requiring potentially heavy pressure containment.

Many Stirling cycle machines that have been built and operated can be described as an ensemble of pistons and heat exchangers. A typical arrangement has two pistons and three heat exchangers. The pistons, a displacer and a power piston, affect the fluid motion inside the machine, and the heat exchangers affect the heat transfer from the heat addition and heat rejection devices and heat flows internal to the engine. In order to obtain net positive work from the power piston, the displacer and power pistons are not in phase with each other. This phase difference is manifested in the two major categories of Stirling engines: the kinematic and the free-piston (West, 1986).

For the kinematic design, the phase difference is controlled by a mechanical linkage, such as a crankshaft or a swash-plate, between the displacer and the power piston. The mechanical linkage usually penetrates the system fluid boundary containment, and thus poses a potential path for fluid leakage. For the freepiston design, there is no direct mechanical linkage between the two pistons-the necessary phase difference is determined by the varying pressures in the cycle and the dynamic response of the components. The free-piston design can result in a hermetic containment with no fluid inventory losses, but the lack of a mechanical linkage between the displacer and power piston may result in non-optimum performance (West, 1986).

Stirling engines have been proposed and developed for a myriad of applications (Walker, 1980; Simon and Seume, 1990). West (1986) summarizes these concepts into groups that include underwater power units, space power units, remote location power units, military ground power units, and automotive power units. For all these application categories, the relative advantages of the Stirling cycle (flexible heat source, low noise, low vibration, high efficiency) are considered against the relative disadvantages (low power density, low effective heat transfer rate). For underwater propulsion, the advantage of low acoustic signature is compelling. NASA has seriously considered Stirling cycles because of the external heat source (nuclear, solar) and potential high effic iency advantages. For remote location power applications such as water pumping and navigation beacons, the high efficiency and flexible heat source advantages were strong considerations. The disadvantage of low power density was relatively unimportant for these three applications. 
For the military ground power applications, the power density is a strong consideration. A few low power generator prototypes $(\sim 1 \mathrm{~kW})$ have been investigated for the military, but were not continued for nontechnical reasons (West, 1986). For the low power range of approximately one kilowatt, the Stirling cycle may have advantages over other engine concepts that should be reevaluated for technical reasons. The difficulty of leaks due to high working fluid pressure may not be a disadvantage in this low power range.

The automotive industry has periodically considered Stirling cycle engines for transportation, but for a variety of reasons, most notably low power to weight ratio and no clear regulated emissions advantage over existing technology, the Stirling cycle has yet to appear in a configuration acceptable to the automotive industry (Amann, 1999; Belaire et al., 1997; Wilson, 1978). The unavoidable operational characteristic of a delay during start-up to heat the machine from ambient to operating temperature would most likely be unacceptable to consumers.

The Stirling cycle offers characteristics worth considering after careful analysis of all the advantages and disadvantages. West (1986) presents some innovative Stirling engine concepts for some very specific applications, and concludes with the following paragraph.

"Several techniques have been described, and there are others not included here, for overcoming the practical difficulties of putting the Stirling principle to use in various applications. These methods tend to impose other design limitations-such as low pressure or speed- that may be acceptable, or even desirable, in specific cases, while preventing a broader application."

After much investigation and many innovative designs, the advantages of Stirling machines seem compelling only if a multifuel capability is needed, including the use of nuclear or solar energy. Portable power production appears worthwhile only for the low power range of approximately one kilowatt because the difficulty of working fluid leakage due to the necessary pressure differences throughout the cycle may not be a disadvantage in this low power range.

Advantages: Potentially high thermal efficiency. Fairly insensitive to fuel or fuel quality. No lubricants needed; the working fluid can support bearing loads.

Disadvantage: High cost, which may decrease as less expensive materials are used and more units are produced. Low power density and low power-to-weight ratio. Working fluid leakage and sealing.

\section{References:}

Amann, C. A., 1999, “Past Experiences with Automotive External Combustion Engines, ”Journal of Engineering for Gas Turbines and Power, Vol. 121, pp. 546-550.

Belaire, R.C., Lawrie, R. E., and Skellenger, G.D., 1997, “Energy Converters for the PNGV Vehicle,” Society of Automotive Engineers, Technical Paper 972677.

Simon, T.W., and Seume, J.R., 1990, "The Stirling Engine: An Engine that Requires High-Flux Heat Exchange under Oscillating Flow Conditions, " Compact Heat Exchangers, R.K. Shah, A.D.Kraus, and D. Metzger, eds. Hemisphere Publishing, New York, pp. 567-626.

Walker, G., 1980, Stirling Engines, Clarendon Press, Oxford.

West, C.D., 1986, Principles and Applications of Stirling Engines, Van Nostrand Rheinhold, New York.

Wilson, D. G., 1978, "Alternative Automobile Engines," Scientific American, Vol. 239 (1), pp. 39-49. 
Websites of Stirling engine vendors:

http://www.sunpower.com/

http://www.whispergen.com/

\subsection{Rankine Cycle.}

The Rankine cycle first starts with the adiabatic compression of a liquid from $P_{l}$ to $P_{h}$, heating at constant pressure from $T_{l}$ to $T_{h}$ including a change in phase from liquid to vapor, adiabatic expansion to produce work, then cooling at constant pressure to complete the cycle which includes a change in phase from vapor to liquid. This Rankine cycle was one of the first cycles to show acceptable performance, primarily because pressurizing a liquid is both easy and efficient. The primary working fluid used here is water, because of its availability, although Rankine cycles have been proposed with such other working fluids as chlorofluorocarbon refrigerants and liquid metals such as mercury and potassium.

The Rankine Cycle can be operated in a closed configuration where the expander exhaust is condensed to liquid before pressurization, or in an open configuration where the expander exhaust is simply discarded to the atmosphere and fresh liquid is supplied to the pressurizer (pump). One notable example of a closed Rankine cycle is a fossil or nuclear steam plant for generating electricity. One example of an open Rankine cycle is the obsolete steam locomotive of the late $19^{\text {th }}$ and early $20^{\text {th }}$ century.

The Rankine cycle offers a very low compression work requirement (pump), a small heat addition device (evaporator), a small expander (turbine or piston), but generally a large condenser is needed to close the cycle. This large condenser makes the closed steam Rankine cycle undesirable for portable power production. In an open configuration, exhausting the steam to ambient conditions wastes potential energy. An open Rankine cycle would also need a source of fresh water at the pump inlet to make up for the exhaust steam discarded to ambient. In addition, the upper limit of temperature in a steam Rankine cycle is approximately $1050^{\circ} \mathrm{F}$ at the expander inlet-above this temperature steam becomes corrosive for metallic components. At best, the Rankine cycle thermal efficiency is $30 \%$ when simple components are used to minimize size. A gain in efficiency is possible when recovery heat exchangers are employed, at the expense of additional cost and size.

The Stored Chemical Energy Propulsion System (SCEPS) torpedo motor developed by Penn State is actually a closed Rankine cycle (Hughes, et. al., 1981). This is an ideal applic ation for the Rankine cycle in that the water surrounding the torpedo can cool the engine and only a relatively smaller condenser is needed. Also, fuel in the SCEPS engine is liquid-metal interaction having a very high energy density and a minimal volume of exhaust products. To convert the SCEPS to burn diesel fuel is possible but eliminates much of the advantages of the system. In addition, if the condenser is modified to use air as the cooling medium as would be necessary for a terrestrial gen-set, the required size would be very large.

Advantages: Mature and well known technology. External combustor can use almost any fuel and can have low emissions and signatures. Commonly available working fluid, although closed system requires very high quality.

Disadvantages: High manufacturing cost, mediocre thermal efficiency, large components, potential freezing of working fluid during cold weather. 


\section{References:}

Wilson, D. G., 1978, “Alternative Automobile Engines,” Scientific American, Vol. 239 (1), pp. 39-49.

Amann, C. A., 1999, “Past Experiences with Automotive External Combustion Engines, ” Journal of Engineering for Gas Turbines and Power, Vol. 121, pp. 546-550.

Hughes, T. G., Smith, R. B., Kiely, D. H., “A Stored Chemical Energy Propulsion System (SCEPS) for Underwater Applications - Its Development and Future”, AIAA-SAE-ASME $17^{\text {th }}$ Joint Propulsion Conference, July 27-29, 1981, Colorado Springs, CO.

Website for SCEPS engine: http://www.arl.psu.edu/areas/sceps/sceps.html

\subsection{Brayton Cycle (Gas Turbine)}

The Brayton cycle or gas turbine starts with adiabatic compression of a vapor from $P_{l}$ to $P_{h}$, heating at constant pressure $P_{h}$ to $T_{h}$, adiabatic expansion to produce work from $P_{h}$ to $P_{l}$, then cooling at constant pressure $P_{l}$ to complete the cycle. Although the thermodynamic processes of the Brayton cycle and the Rankine cycle appear the same, the main difference is the compression process. The Rankine cycle pressurizes a liquid, while the Brayton cycle pressurizes a vapor. Pressurizing a vapor is more difficult (and requires more power) than pressurizing a liquid. The thermal efficiency of Brayton cycle machines is very dependent on the compressor and expander individual component efficiencies, which tend to decrease as the size decreases. The key advantage of Brayton cycle machines is their high power density. The major disadvantage to date has been the relatively high cost.

\subsubsection{Open Cycle Configuration}

The Brayton cycle engine can be configured as either a closed or open cycle. An open cycle configuration would compress atmospheric air to a high pressure, add heat by direct combustion of fuel, expand the high-energy combustion gases through a turbine, then exhaust the low-pressure combustion gas to ambient. This engine is commonly found in jet aircraft in various configurations. High performance aircraft use only enough expansion energy to power the compressor - the remainder is used for thrust. Subsonic aircraft use the remainder of the expansion energy to spin a propeller or fan. This engine can also be used in an open cycle for production of shaft power for electrical power generation, and many combustion gas turbines are in use to generate electricity for terrestrial applications. In some of these terrestrial applications, a heat exchanger, called a recuperator or regenerator, recovers heat in the turbine exhaust flow and transfers it to the compressor outlet flow before the combustor. This recuperator can usually double the efficiency of the open Brayton cycle, but it can increase the size and cost. The use of a recuperator is usually dictated by economics, i.e., the capital cost of the recuperator versus the operating cost of the fuel.

Originally, open Brayton cycle engines were adapted from aircraft (aeroderivatives), and as such have a substantial output on the order of a megawatt or more. Presently, open Brayton cycle engines are actively being developed and marketed for electrical power production in sizes of approximately $30 \mathrm{~kW}$, and have been arbitrarily designated as "microturbines." One company actively researching and developing this size concept for portable power electrical power generation, including transportation, is Capstone Turbine Corporation Other researchers at MIT (Drake, 1997) are currently developing a $1 \mathrm{~kW}$ combustion gas turbine, also designated a "microturbine," that offers the promise of very compact power generation. Much work remains to be done to realize this very small (the size of a shirt button), very powerful machine in hardware. Even though closed Brayton cycle machines offer the promise of higher thermal efficiency, they are more costly and require more volume because of the additional heat exchangers necessary to close the cycle. The Brayton cycle in its various configurations offers a realistic and achievable heat engine for high power and efficiency. 


\subsubsection{Closed Cycle Configuration}

The Brayton can also be used in a closed cycle configuration, where the working fluid strictly flows inside the engine. For the closed configuration, heat is added through a heat exchanger after the compressor and the turbine exhaust flows through a recuperative heat exchanger and another heat exchanger to reject heat to ambient. This additional heat exchanger hardware increases the volume and footprint of the Brayton cycle engine, but additional advantages can result. The working fluid need not be air, and closed Brayton cycles have been designed and operated with such inert working fluids as helium and neon. Helium is a particularly good working fluid, resulting in a potentially very high power density. Because the heat is added external to the cycle through a heat exchanger, any heat source or fuel can be used.

The two configurations differ in the manner for varying the power output, such as load following. The open cycle can either vary the turbine inlet temperature or the shaft speed. Decreasing the turbine inlet temperature will result in a significant decrease in thermal efficiency. Varying the shaft speed is preferable if the generator electrical power characteristics can be conditioned, although a drop in efficiency also results but not as large as decreasing the turbine inlet temperature. The closed cycle can respond more readily to load following while maintaining a constant thermal efficiency and constant shaft speed because the shaft power output is directly proportional to the mass flow rate, which is easily varied by changing the working fluid inventory. The working fluid inventory can easily be changed by placing an accumulator across the compressor with appropriate valves to either admit stored inventory to increase output or remove inventory to decrease output. The amount of fluid inventory (total mass) affects the working pressure level, which affects the mass flow rate, which is directly proportional to output power. In summary, both open and closed Brayton cycles respond to load following: the open cycle can respond quicker but at a loss in thermal efficiency, and the closed cycle responds slower to load changes but at no decrease in thermal efficiency

Advantages: These continuous flow machines offer a high power density, and a respectable efficiency at full load on the order of $30 \%$ for the open cycle, and even higher for the closed. Brayton cycles are fairly insensitive to fuel quality. The sizes considered for this study also have a distinct advantage over other methods in that the rotating components can be supported by air bearings in any orientation. Thus, no auxiliary lubricating fluid or oil is needed.

Disadvantage: The primary disadvantage is cost. Although expensive alloys are now used, the cost will decrease as less expensive materials are used and more units are produced.

\section{References:}

Amann, C. A., 1999, “Evaluating Alternative Internal Combustion Engines: 1950-1975, ” Journal of Engineering for Gas Turbines and Power, Vol. 121, pp. 540-545.

Belaire, R.C., Lawrie, R. E., and Skellenger, G.D., 1997, “Energy Converters for the PNGV Vehicle,” Society of Automotive Engineers, Technical Paper 972677.

Craig, P., 1997, “The Capstone Turbogenerator as an Alternative Power Source," Society of Automotive Engineers, Technical Paper 970292. See also http://www.capstoneturbine.com/.

Drake, J., 1997, “Shirt-Button Turbines,” Technology Review, January/February 1997. Available at http://www.techreview.com/articles/jf98/reporter.html.

Rogers, C., and McDonald, C.F., 1997, “Automotive Turbogenerator Design Considerations and Technology Evolution,” Society of Automotive Engineers, Technical Paper 972673. 
Wilson, D. G., 1997, “A New Approach to Low-Cost High Efficiency Automotive Gas Turbines, ” Society of Automotive Engineers, Technical Paper 970234.

Wilson, D. G., 1978, “Alternative Automobile Engines,” Scientific American, Vol. 239 (1), pp. 39-49.

\subsubsection{Active Working Fluid Cycle.}

The thermodynamic cycle processes of this experimental cycle are identical to those of the Brayton cycle, and all the advantages of the closed Brayton cycle are also applicable here. The major difference for this cycle is that a large molecular weight fluid is compressed, then heat is added to dissociate chemically the working fluid into a lighter molecular weight for expansion in a turbine, where the turbine exhaust is then cooled and the light molecular weight components chemically recombine into a high molecular weight fluid at the compressor inlet. In a sense, this cycle combines the low compression work requirement of the Rankine cycle with the high expansion work output of the Brayton cycle. This will potentially result in high thermal efficiency and very high power density. Interestingly, the principle behind this active working fluid of compressing a heavy molecule and expanding a light molecule can also be applied to the Stirling cycle (Metwally and Walker, 1977) or Rankine cycle (Kesavan and Osterle, 1982).

The initial idea for applying dissociating fluids in power cycles appears to have originated by Lighthill (1957) during a very theoretical analysis of sonic flow phenomena of dissociating fluids. During the 1960's, Russian investigators applied chemically dissociating fluids as heat transfer fluids for the fast nuclear reactor program, and also investigated dissociating fluids as the working fluid in Brayton and Rankine cycles for very large power generation stations of approximately $100 \mathrm{MW}$ and larger. Summary publications by Krasin and Nesterenko (1971) and Krasin (1975) document this research. A number of advantages for using dissociating fluids in power generation cycles were reported, specifically including high thermal efficiency, small rotating turbomachinery, and very small heat exchange equipment. The Russian fast nuclear reactor program was canceled, so all research and development for this concept in Russia also was halted.

The high thermal efficiency of an active working fluid cycle results from the lowered compression work input, and the small turbomachinery and heat transfer equipment result from favorable thermophysical properties. One very interesting property is the thermal conductivity, which is a measure of the speed of transferring heat by a substance. In general, the lower the thermal conductivity of a substance, the more heat transfer surface is needed, which leads to a larger and heavier heat exchanger. For a dissociating fluid, an enhancement in thermal conductivity results from the chemical reaction during either heating or cooling (Brokaw, 1961), thus heat transfer equipment using these fluids will be smaller for the same or higher heat duty than an inert working fluids. Hence, this active working fluid cycle has the potential of a high thermal efficiency and a high power density (Stochl, 1979).

One major question to be answered for feasibility of this concept is the rate of chemical reaction. In order for this AWF cycle to be advantageous, the working fluid must dissociate and recombine as appropriate during the temperature and pressure changes of the thermal power conversion cycle, and also not generate stable chemical species during these changes in thermodynamic state. Another concern is materials compatibility, since these dissociating fluids are by necessity chemically active. So feasibility and development of this very experimental cycle is currently undergoing investigation at ORNL. Significant research and development effort is needed to address the chemical kinetics and stability of the active working fluid, and to evaluate appropriate turbomachine designs in order for this concept to realize its potential. This concept does hold the promise of a very compact, efficient thermal power conversion device, but not for several years.

Potential Advantages: Very high power density, high thermal efficiency. 
Disadvantages: Unproven technology, potentially toxic materials.

\section{References:}

Brokaw, R. S., 1961, “Thermal Conductivity and Chemical Kinetics,” J. Chemical Kinetics, Vol. 35, pp. 1569-1580.

Kesavan, K., and Osterle, J.F., 1982, Split-Flow Nuclear Gas Turbine Cycle Using Dissociating $\mathrm{N}_{2} \mathrm{O}_{4}$, Paper 82-GT-181, The American Society of Mechanical Engineers, New York.

Krasin, A.K., and Nesterenko, V. B., 1971, "Dissociating Gases: A New Class of Coolants and Working Substances for Large Power Plants,” Atomic Energy Review, Vol. 9, pp. 177-194.

Krasin, A.K., 1975, Dissociating Gases as Heat-Transfer Media and Working Fluids in Power Installations, AEC-tr-7295, translated and published for the Atomic Energy Commission and the National Science Foundation by Amerind Publishing, New Delhi.

Lighthill, M.J., 1957, “Dynamics of a Dissociating Gas Part I Equilibrium Flow, ” J Fluid Mechanics, Vol. 2, pp. 1-32.

Metwally, M.M., and Walker, 1977, "Stirling Engines With a Chemically Reactive Working Fluid-Some Thermodynamic Effects,” Journal of Engineering for Power, pp. 284-287.

Stochl, R.J., 1979, Potential Performance Improvement Using a Reacting Gas (Nitrogen Tetroxide) As The Working Fluid in a Closed Brayton Cycle, NASA TM-79322.

\subsection{Ericsson Cycle.}

The Ericsson cycle starts with isothermal (constant temperature) compression of a vapor from $P_{l}$ to $P_{h}$, heating at constant pressure $P_{h}$ to $T_{h}$, isothermal expansion to produce work from $P_{h}$ to $P_{l}$, then cooling at constant pressure $\mathrm{P}_{1}$ to complete the cycle. Adding cooling heat exchangers to the compressor and adding heating to the turbine of a Brayton cycle can approximate this cycle. This additional heat exchange equipment (with the additional pressure losses) makes the Ericsson cycle impractical in comparison to the Brayton cycle with rotating turbomachinery. Ericsson cycle machines have been built using reciprocating components, but these have also been impractical (Dey, 1964). Also, an isothermal compression or expansion in a machine operating at a reasonable speed is difficult to achieve (Van Wylen and Sonntag, 1965).

No practical Ericsson cycle machines appear to be in operation or development, but the cycle is interesting from a theoretical viewpoint. The upper limit of the thermal efficiency of an Ericsson cycle can be shown to be identical to the Carnot limit. Thus, the reward of theoretically maximum thermal efficiency is possible, although not practically achievable as yet. This concept is therefore not evaluated.

Potential Advantage: Very high thermal efficiency.

Disadvantage: Unproven technology. 


\section{References:}

Dey, N.C., 1964, Heat Engines and Applied Thermodynamics, Asia Publishing, New York, p. 78.

Van Wylen, G.J., and Sonntag, R.E., 1965, Fundamentals of Classical Thermodynamics, John Wiley, New York, pp. 300-301.

\subsection{Atkinson Cycle}

The Atkinson cycle starts with adiabatic compression of a vapor from $P_{l}$ to an intermediate pressure $\mathrm{P}_{i}$, heating at a constant volume to the high pressure $\mathrm{P}_{h}$ and $\mathrm{T}_{h}$, adiabatic expansion to produce work from $\mathrm{P}_{h}$ to $\mathrm{P}_{l}$, then cooling at constant pressure $\mathrm{P}_{l}$ to complete the cycle. It can be rigorously proved that the thermal efficiency of the ideal Atkinson cycle is always higher than the thermal efficiency of the ideal Otto, Diesel, or Brayton cycles for a given compression ratio (Bussing and Pappas, 1994; Heywood, 1988). The reason that the Atkinson cycle has a higher efficiency than the Otto cycle or the Diesel cycle is that a complete expansion to ambient pressure is performed, and thus no potential energy is wasted during the exhaust process from a pressure higher than ambient as is necessary for the Otto or Diesel cycles. The reason that the Atkinson cycle has a higher thermal efficiency than the Brayton cycle is that the constant volume heat addition results in a higher expander inlet pressure and temperature than the constant pressure heat addition process of the Brayton cycle. Interestingly, the thermal efficiency and power density at a constant shaft speed are a function of the load for this ideal cycle, which is not the case for the gas turbine. This inherent characteristic allows for fast load changes at constant speed by simply modulating the fuel flow rate, which is an easily controlled parameter.

Some machines operating on the Atkinson cycle have been proposed and tested. The traditional piston internal combustion engine operating on the Otto cycle can be modified to operate on the Atkinson cycle, but at an additional cost of increased valve mechanism complexity. Also, the power density of this piston configuration of the Atkinson cycle is not advantageous (Heywood, 1988). Thus the Atkinson cycle has not been generally adapted by the piston reciprocating internal combustion engine manufacturers.

The combustion gas turbine can be modified to become an Atkinson cycle device by including a freerunning rotor between the compressor and the expander (Wilson and Korakianitis, 1998). This particular configuration has been called a pulse detonation engine (Bussing and Pappas, 1994) because of the intermittent combustion event that takes place in the free-running rotor at sonic velocities. Although this particular concept has seen some research for aircraft propulsion, further research is needed (Kailasenath et al., 1999) to resolve unsteady loss problems.

A recent invention (Wilson, 1999), a rotating turbomachinery device that operates on the Atkinson cycle, was recently brought to ORNL for evaluation. This particular device cleverly employs the compression, constant volume combustion, expansion and constant pressure expansion processes on one rotating wheel. This particular concept should not have the unsteady loss problem of the pulse detonation engine because supersonic waves are not needed for combustion. Because of the rotary configuration, this concept will not have the disadvantageous power density of the reciprocating piston variation of the Atkinson cycle. Indeed, preliminary analysis of the ideal cycle thermodynamics by ORNL personnel shows that this version of the Atkinson cycle has a power density per unit mass of working fluid greater than that of the ideal Brayton cycle for a given compression ratio. A $15 \mathrm{~kW}$ demonstration model of the design has been fabricated and successfully tested under very limited conditions.

Thus, the Wilson configuration of the Atkinson cycle has a very high potential for a heat engine to provide mobile power because of its high efficiency and high power density. For a practical engine, however, there are a number of design and operating characteristic s that need to be considered and tested. 
The non-ideal, real world considerations of friction and unavoidable heat losses will result in a lessening of the ideal efficiency of this like any other thermodynamic cycle, and these non-ideal considerations must be quantified and considered in a practical machine. This Wilson engine has the potential for improving the fuel efficiency of rotating turbo-machine thermal power conversion devices while decreasing the physical size for a given load. Further analytical and experimental investigation of this concept is highly recommended. This engine design merits further independent testing to quantify the performance characteristics.

Advantages: high thermal efficiency, high power density

Disadvantages: experimental concept.

\section{References:}

Bussing, T., and Pappas, G., 1994, "An Introduction to Pulse Detonation Engines, " Paper AIAA 94-0263, The American Institute of Aeronautics and Astronautics, Washington, D.C.

Heywood, J. B., 1988, “Internal Combustion Engine Fundamentals”, McGraw-Hill, New York, NY, pp. 183-186.

Kailasanath, K., Patrick, G., and Li, C., 1999, “Computational Studies of Pulse Detonation Engines - A Status Report”, Paper AIAA 99-2634, The American Institute of Aeronautics and Astronautics, Washington, D.C.

Wilson, D. G., and Korakianitis, T., 1998, "The Design of High-Efficiency Turbomachinery and Gas Turbines," 2nd edition, Prentice-Hall, NJ, pp. 162-163.

Wilson, M. W., 1999, “Efficiency Enhanced Turbine Engine,” United States Patent number 5,966,927, October 19, 1999.

\subsection{Diesel Cycle (Compression Ignition)}

The Diesel cycle, or compression ignition cycle, starts with adiabatic compression of a vapor, heating at constant pressure, adiabatic expansion to produce work, then cooling at constant volume to complete the cycle. This cycle is similar to the Otto cycle (described in following sections), except that the combustion event is initiated by high-pressure injection of liquid diesel fuel into the combustion chamber after compressive heating of the inlet air to a sufficiently high temperature.

This cycle also has had extensive development over the past century, and its advantages and limitations can readily be quantified. Deviations from ideal are due to the following: heat transfer during the compression and expansion process, and the heat addition cannot be at a constant pressure due to limitations on fuel injection and combustion rates. The efficiency of the Diesel cycle is directly related to the compression ratio, which can be quite high for diesel fuel use (18-23:1 versus 8-10:1 for Otto cycle gasoline engines). Diesel cycle engines have very good efficiency throughout a range of operating speeds. State-of-the-art diesel engine construction is somewhat heavier than gasoline engines because of the higher stresses caused by the high compression ratio.

Despite the long history behind the diesel engine, significant improvements and innovations continue today. In the current marketplace, over $99 \%$ of all diesel engines are the 4-stroke, reciprocating design. This and other designs are discussed briefly, and some of the latest improvements are cited in the following sections. 


\subsubsection{Four-Stroke Reciprocating Engines}

The common diesel engine, a 4-stroke reciprocating engine, is known to be a very rugged prime mover with moderate maintenance requirements and excellent fuel economy. The reciprocating diesel engine industry is widespread in the U.S. and other places, and a good support base exists for sales, service, applications and repair. Diesel engine driven gen-sets are the standard for comparison with all other dieselfueled generator concepts. Currently, there is broad application for commercial and military use of diesel engines and dieseldriven gen-sets in many parts of the world. For most gen-set applications and for most non-vehicle diesel engine applications, weight and volume are not primary considerations.

Diesel engines in the size range of interest are often categorized as industrial engines or automotive engines, although no strict boundary lines truly exist. Generally, much more emphasis is put on achieving high power-to-weight and fuel economy for automotive applications, and due to the very high volumes of engine sales (especially in Europe), much resources are being put into developing superior automotive diesels. The best power-to-weight ratio engines are the very latest European automotive diesel engines that feature cooled-charge turbochargers, high-pressure electronically-controlled fuel injection, lightweight design and materials, and sometimes 4 valves per cylinder. The 3 or 4 cylinder units being used in European cars could be attractive for the $15-30 \mathrm{~kW}$ gen-set size range. More small automotive engines are being developed for the European mini-car and city-car market.

The best available engines for gen-sets under $15 \mathrm{~kW}$, have significantly less power-to-weight than the automotive-designed engines. A few small 3-cylinder engines are offered with turbochargers and may be suitable for $10-15 \mathrm{~kW}$ gensets. Turbocharging generally increases power-to-weight by $30 \%$ or more and reduces power-to-volume as well. Power-to-weight drops further for 1 or 2 cylinder diesel engines currently available and suitable for gen-sets with under about $10 \mathrm{~kW}$ output. These small industrial diesel engines are not turbocharged (technically this would be very difficult). A few 2-cylinder engines feature aluminum crankcase design to reduce weight.

Advantages: Very mature and widespread technology, relatively low cost and high reliability, high efficiency (fuel economy of 200-250 g/kWh for modern engines), long life, relatively low thermal signature. Power density of the prime mover (only) is 100 to $400 \mathrm{~W} / \mathrm{kg}$ over the $1-40 \mathrm{~kW}$ power output range. Initial cost is about $\$ 100$ to 250 per $\mathrm{kW}$, and operating costs are low. Can meet EPA emission standards.

Disadvantages: Can produce high noise and vibration, which increases with rotational speed.

Other comments: More use of aluminum and magnesium components may be possible in the future. The maximum operating speed range is $3600-5000 \mathrm{rpm}$ and this will not change appreciably due to the reciprocating components mass. It is feasible to design significantly lighter engines that have a somewhat lower compression ratio, lower efficiency, and shorter life expectancy. There is currently very little demand for short-life engines, and diesel engines have traditionally been built for very long life and high reliability.

\section{References:}

Robin America, Inc. Wood Dale IL. www.robinamerica.com.

ORNL Report, “Advanced Power Generation Systems for the $21^{\text {st }}$ Century, Market Survey and Recommendations for a Design Philosophy” ORNL/TM-1999/213, Prepared for the Communication and Electronics Command - Research, Development, \& Engineering Center, Fort Belvoir, VA, Oak Ridge National Laboratory, Oak Ridge, TN, November, 1999. 


\subsubsection{Two-Stroke Reciprocating Engines}

Two-stroke engines are of interest because of their potential to deliver more power from the same sized engine when compared to a four-stroke engine. Although one may expect about twice the power from a two-stroke versus a four-stroke engine of the same displacement, this is not the case. The two-stroke engine has difficulty adequately exhausting combustion products and re-charging the cylinder with fresh air. For engine sizes of interest to this study, special turbocharging and/or supercharging are required and this air compression process has a modest efficiency penalty compared to four-stroke engine turbocharging. Other drawbacks include more difficulty controlling emissions, a greater need for cooling certain components and special considerations for air-intake and exhaust system design.

Currently most of the two-stroke diesel engines being marketed by major engine manufacturers are very large, and used for applications such as ocean vessels. However, one manufacturer, Daihatsu, has announced a new advanced two-stroke engine model to be used for powering very small cars (likely in 2001) in markets outside the U.S. Based on manufacturer's information from press releases, this engine appears to have a 10-25\% weight advantage over the closest competitor's (VW) comparatively sized engine. Power-to-weight ratio is 200 to $250 \mathrm{watts} / \mathrm{kg}$. No two-stroke diesel engines in the size range of interests are currently EPA certified or marketed for sales in the U.S.

An engine study was performed by Southwest Research Institute to design and demonstrate a heavy-fuel engine suitable for unmanned aerial vehicles. A major conclusion of this study was that a compression ignition 2-stroke engine using a piston-type air compressor system was a good design approach. The piston compression system does the task of a supercharger and allows adequate exhaust removal and fresh charge intake. A two power-cylinder engine with two air compressor cylinders was built and tested. This initial prototype produced about $10 \mathrm{~kW}$ (net power) at $3000 \mathrm{rpm}$, and weighed about $19 \mathrm{~kg}$ (power/weight $\sim 540$ watts $/ \mathrm{kg}$ ). Work was stopped when the initial prototype failed during testing. The effort was an internally funded project, which met a major purpose of demonstrating engine prototyping capability (power/weight $\sim 1000$ watts $/ \mathrm{kg}$ ). The design analysis indicated that this engine could likely be optimized to produce over $20 \mathrm{~kW}$. No conclusions can be made about emission, life or maintenance of this engine, but fuel economy should be comparable to other small diesel engines.

\section{References}

Ward's Engine and Vehicle Technology Update, Vol. 25, No. 19, Oct 1, 1999.

Daihatsu Webpage: http://www.ingway.co.jp/ daihatsu/motorshow/tokyo99/2cd/

S. K. Widener et. al, (Southwest Research Institute) "A Heavy-Fueled Engine for Unmanned Aerial Vehicles, " SAE Paper 950773, SAE International Congress and Exposition, Detroit, Feb. 27-March 2, 1995.

Personal communication with Robert W. Burrham, Program Manager, Engine Research Department, Southwest Research Institute, San Antonio, TX, February 2000.

\subsubsection{Rotary Compression Ignition Engines}

Experience with rotary spark ignition (Otto cycle) gasoline engines, shows there can be a power-toweight ratio advantage for rotary engine designs versus reciprocating designs. However, the rotary spark engine appears to have somewhat of a fuel economy and emission production disadvantage. The power density advantage and fuel economy disadvantage would also be expected for a diesel cycle rotary engine in comparison to reciprocating designs, but little verifiable information is available. 
One small development company, Patrick Power Products, is testing compression-ignition rotary diesel fueled engines, and the target market is lightweight power generation. Apparently only a few prototypes have been built and are being tested, therefore limited information has been obtained by ORNL at this time. No major engine companies are known to be working on such a device. The developmental rotary compression ignition device is claimed to have power-to-weight a ratio 2-3 times higher than the best reciprocating diesel engines. According to an inquiry and test results reported to CECOM, fuel consumption is roughly 2 or more times than expected for a modern reciprocating diesel engine.

\section{Advantages}

Advantages may include excellent (shaft) power density claimed, 400-800 W/kg, 30\%-60\% less volume than reciprocating diesel, and relatively low acoustic signature. Maximum operating speeds of 5000-9000 rpm are claimed.

\section{Disadvantages}

Fuel consumption is reported to be roughly $500 \mathrm{~g} / \mathrm{kWh}$, more than double modern reciprocating diesel engines. The technical risk is relatively high and costs would be high due to the low number of engines built. Exhaust emissions may violate EPA diesel engine standards. This technology is unproven at this time.

\section{References:}

Personal communication with Steve Huter, President of Patrick Power Products $\left(\mathrm{P}^{3}\right)$, Elkridge, MD, June 1999. Letter from Steve Huter dated June 23, 1999.

\subsection{Otto Cycle}

The Otto cycle starts with an adiabatic compression of a vapor, heating at constant volume, adiabatic expansion to produce work, then cooling at constant volume to complete the cycle. The most prevalent example of an Otto cycle is the typical spark ignition gasoline automobile engine. This cycle is best realized with internal combustion engines where the heat rejection is accomplished by releasing the combustion products to ambient in an open cycle. Reciprocating piston engines are typical, but some rotary concepts have been developed. The combustion of the compressed vapor is most often initiated by a spark.

This cycle has had extensive development over the past century, and its advantages and limitations can readily be quantified. Deviations from ideal are due to the following: heat transfer during the compression and expansion process, and the heat addition occurs over a finite time interval, which thus cannot be at a constant volume. The efficiency of the Otto cycle is directly related to the compression ratio, but the combustion characteristics of the fuel put an upper limit on achievable efficiency values. Otto cycle engines have good efficiency throughout a range of operating speeds, and can be made light in weight with low manufacturing costs.

Typically Otto cycle (or spark ignition) engines burn gasoline rather than diesel fuel. Gasoline is formulated to help optimize the performance of spark ignition engines. Suitable fuels other than gasoline are also utilized in spark ignition engines, including natural gas and alcohol based fuels. In contrast to gasoline, diesel fuel is formulated to be an excellent compression ignition fuel and purposefully has a relatively low vapor pressure (to prevent fires and explosions in the fuel systems and to prevent evaporation) resulting in an inherently poor spark ignition fuel. The Otto cycle can be realized with diesel fuel, but the fuel must be vaporized before the compression and ignition steps. Vaporization of diesel fuel may be a difficult added step, requiring added complexity. The reliable use of diesel fuel over a long time interval in a spark-ignition Otto cycle engine is unproven at this time. 
Although there are no known fully commercial engines currently available using spark ignition with diesel fuel, a few developers have pursued the difficult task of using spark ignition with diesel fuel. The incentive is to develop a lightweight diesel fueled engine, very similar to a gasoline engine. To create a workable spark ignition dieselfueled engine generally requires the fuel and/or combustion air to be preheated and/or pre-treated to allow effective spark ignition. Any spark system must be more powerful than that used for gasoline engines, and would be subject to higher wear and EM signature. Such an engine would likely employ low compression ratios typical of an Otto cycle, achieve much lower efficiency compared to a diesel cycle, and have difficulty meeting EPA emission standards.

This spark ignition approach is being explored by developers for both reciprocating 2-stroke and rotary 4stroke engines. Past and on-going development for military applications is cited by the developers. No useful information has been obtained for developmental reciprocating spark ignition, 4-stroke diesel fueled engines. There is probably less interest due to lighter weight options when compared to 2-stroke or rotary diesel engines.

\subsubsection{Two-stoke Reciprocating Spark Ignition Engines}

Successful demonstrations have been reported (by Even Guy Enterprises, Inc.) for a reciprocating engine in an unmanned aerial vehicle application. Power density was reported to be near 750 watts $/ \mathrm{kg}$ for a single cylinder prototype engine and it is claimed this will double (1500 watts $/ \mathrm{kg})$ for an optimized, 37 $\mathrm{kW}, 2$ cylinder engine. Fuel consumption was reported near $400 \mathrm{~g} / \mathrm{kWh}$ (about $60 \%$ higher than a small diesel engine).

\section{Advantages}

Engine is potentially very lightweight and low volume for sizes in the $10-30 \mathrm{~kW}$ range. Some conventional parts could be used in this engine (pistons, linkages, etc.). Documented UAV tests have been run for the U.S. military for a prototype.

\section{Disadvantages}

Little information concerning the technical success of these engines is available so risk and cost must be considered as high until shown otherwise. The use of a spark to ignite heavy fuel will likely decrease reliability. Fuel consumption appears to be at least $75 \%$ more $(\sim 400 \mathrm{~g} / \mathrm{kWh})$ than a modern reciprocating diesel. Thermal signature will be increased over a diesel engine and EM signature may be high due to the spark ignition devices required. It may be very difficult for emissions to meet EPA spark engine or diesel engine standards. This engine will not be quiet but may not be as loud as compression ignition engines.

\section{References:}

Website for Sonex Research, Inc. Annapolis, MD 21401, http://www.sonexresearch.com/.

Personal communication with Robert W. Burrahm, Program Manager, Engine Research Department, Southwest Research Institute, San Antonio, TX, February 2000.

Personal communication with Even Guy and Thomas A. Kuchnicki, Even Guy Enterprises, Inc., 7231 Maple Drive, Alanson, MI, February, 2000.

\subsubsection{Rotary Four-Stroke Spark Ignition Engines.}

There is at least one company developing prototype rotary, four stroke, and spark ignition assisted heavyfuel engines. Literature from Wankel Rotary $\mathrm{GmbH}$ indicates they can achieve very high power to weight, with claimed values of 1300 watts $/ \mathrm{kg}$ for a single rotor turbocharged engine producing $37 \mathrm{~kW}$ at 
$6000 \mathrm{rpm}$. Fuel consumption is claimed to be near $300 \mathrm{~g} / \mathrm{kWh}$ at the best operating point but more typical values would approach $400 \mathrm{~g} / \mathrm{kWh}$.

\section{Advantages}

Engine is potentially very lightweight and low volume for sizes near $30 \mathrm{~kW}$ and larger. Should be a quiet engine.

\section{Disadvantages}

Very little information concerning the technical success of these engines is available, so risk and cost must be considered as high until shown otherwise. Fuel consumption appears to be at least 50\% more than a modern reciprocating diesel. Thermal signature will be increased over a diesel engine and EM signature may be high due to the spark ignition devices required. It may be very difficult for emissions to meet EPA spark engine or diesel engine standards. The spark ignition system adds complexity and could cause reliability problems.

\section{References}

Website for Wankel Rotary GmbH, Korb, Germany, http://wankelrotary.com/main_e.htm Website for Sonex Research, Inc. Annapolis, MD 21401, http://www.sonexresearch.com/.

Personal communication with Mr. George Brooks, representative for Wankel Rotary GmbH, 30 Country Club Dr., South Burlington, VT 05403.

\subsubsection{Homogeneous Charge Compression Ignition}

Another approach for burning diesel fuel in the Otto cycle is to employ homogeneous charge compression ignition (HCCI). Diesel fuel could be mixed with air and at least partially vaporized by some means to create a relatively homogeneous fuel/air mixture. The HCCI approach is to use a very fuellean mixture in conjunction with a very high compression (usually > 30:1 compression ratio). Compression (and compression heating) causes fuel/air mixture ignition and burning to occur over a very short duration, which more closely approximates a constant volume heat addition.

Most developers of this technology appear to be targeting the stationary applications market for engine sizes larger than the output range of interest. Diesel fuel is not being considered currently for HCCI, because the technology is considered to be a possible means for allowing alternative fuels to compete in certain markets with typical diesel engines.

Analysis of this technology reveals drawbacks for lightweight gen-set applications. The HCCI technology is not suited to following load as well as common diesel engines and would have no weight advantage over typical diesel engines. No developers are considering this technology for diesel fuel applications. For these reasons this technology is not considered further or evaluated.

\subsection{Chemical Energy Conversion (Fuel Cell)}

In addition to heat engines, other prime movers were considered for their applicability to expeditionary power sources. This section described the foundations of chemically reacting a fuel fed into what is essentially a battery and extracting electrical energy directly; or the fuel cell. The fuel cell operates at a constant temperature and is not a heat engine; thus, it is not subject to Carnot limitations.

A great many types of fuel cells have been developed and tested. Fuel cells have already penetrated some small niche markets, including government subsidized demonstrations or space program applications. It 
should be noted that fuel cells have been given a large amount of publicity for a number of years, which has given the impression that they closer to widespread use than is indeed the case.

Fuel cells do offer the potential for a clean, quiet, and efficient power source for portable electric generation. Of the different fuel cell concepts, the phosphoric acid fuel cell (PAFC) and the polymer electrolyte membrane fuel cell (PEM) have received the most attention. The PAFC has been demonstrated in large vehicles such as buses and trucks. However, the PAFC is the least efficient fuel cell and has little potential for being adapted for use in portable applications and is not considered further in this report. PEM fuel cell R\&D is now receiving the most support from the U.S. government and industry. Recently serious questions have been raised about the viability of PEMs to use complex fuels economically and the high cost of manufacturing the fuel cell. Solid Oxide Fuel Cells (SOFC) offer an alternative approach that may avoid some of these issues.

\subsubsection{PEM Fuel Cells}

A candidate technology for (relatively) lightweight fuel cells is known as proton exchange membrane or PEM. This technology is the one usually cited for future use in vehicles. The fundamental component of the PEM fuel cell consists of two electrodes (anode and cathode) separated by the solid polymer membrane electrolyte. The promise of PEM technology stems from the possibility of near-zero emission operation and high efficiency. Efficiencies of up to $60 \%$ (fuel energy content/electrical power output) are cited with use of hydrogen fuel under peak-performing conditions.

Like most fuel cell technologies, a hydrogen rich gas must be supplied to the fuel cell. This means a liquid fuel must be reformed into a hydrogen containing gas. A fuel reformer that reacts diesel fuel with steam to produce a gaseous mixture containing hydrogen is required. Furthermore, the PEM fuel cell cannot tolerate the sulfur (S), which is present in diesel fuel, or carbon monoxide (CO), which is formed by the fuel reforming process. The fuel reformer system will require $\mathrm{CO}$ removal or oxidation (to $\mathrm{CO} 2$ ) and sulfur removal to be viable. These additions are possible but add cost, complexity, weight, and will reduce efficiency.

A fuel cell based gen-set would not be a simple device. In addition to the fuel cell "core" and the fuel supply with the reformer system (with $\mathrm{CO}$ and $\mathrm{S}$ removal) there must be an air management system including a blower (some designs include pressurized air and require a compressor), a water management system, a warm up/startup system, battery, and power electronics.

When compared to gasoline and diesel automotive engines, fuel cells are significantly heavier and much costlier vehicle powering devices. Although the fuel cell would essentially replace both the engine and alternator in a typical genset, the weight and cost currently compare unfavorably. Weight and cost are projected to drop in the future.

\section{Advantages}

Very low acoustic signature, and excellent load following capability. Thermal signature and fuel efficiency should be similar to diesel engine gen-sets.

\section{Disadvantages}

The low fuel cell operating temperatures for these fuel cell, nominally $80^{\circ} \mathrm{C}$ for PEM, are attractive for portable applications. However, some technical issues of concern include:

- the need for pure hydrogen fuel within the fuel cell, either directly or indirectly from a reformer of complex fuels

- the poisoning of the fuel cell, particularly the required catalysts, with $\mathrm{CO}$, and/or other impurities such as sulfur 
- the inability to reform complex transportable fuels to pure hydrogen at the low fuel cell operating temperatures.

\section{References}

Automotive News, “Fuel cells still pose thorny problems,” p. 40, March 29, 1999.

Website for International Fuel Cells, subsidiary of United Technologies Corporation: http://www.internationalfuelcells.com/.

Website for Ballard Power Systems, Inc., http://www.ballard.com/default.asp.

\subsubsection{Solid Oxide Fuel Cells (SOFC)}

The issues associated with PEM fuel cells can be addressed if the fuel cell operating temperature is increaed above $750^{\circ} \mathrm{C}$. Thus consideration can be given to the use of solid oxide fuel cells for applications in automobiles.

SOFC technology has the potential for providing high power densities, long, stable performance lifetimes, the ability to utilize a broad source of fuels without expensive reforming or gas cleanup and provide high system efficiencies for a wide range of power generation for transportation. The materials, fabrication and electrochemical process understanding and fuel cell testing experience is a critical base now available for application to new designs, primarily planar designs, that have the potential for low-cost SOFCs for application to transportation and to related needs.

The potential for very high, simple cycle system efficiencies can utilize a new SOFC concept that can provide system efficiencies of up to $70 \%$. This concept utilizes fuel cells in series, which operate at different temperatures. When combined with other generation cycles, efficiencies of above $80 \%$ appear possible.

\section{Advantages:}

SOFCs offer an alternative to other fuel cell concepts, i.e., PEM, now being developed for transportation. The SOFC has the ability to: 1) reform a wide variety of gaseous and liquid fuels at fuel cell temperatures without catalysts either indirectly or directly by the fuel cell; 2) use CO directly as a fuel, 3) have a high tolerance for fuel impurities, such as sulfur; 4) provide long lifetimes and low degradation rates, 5) operate at both high and very low ambient temperatures and 6) provide high power densities and high fuel efficiencies. Although the cost of state-of-the-art SOFC is currently high, the potential for lowfabrication costs using new designs and modified conventional fabrication methods is very good

\section{Disadvantages:}

SOFCs are not without limitations, one of which is critical and has been the major issue of considering SOFCs as a transportation power source. These limitations are:

-Long start up times necessary to accommodate the thermal mechanical limitations inherent to ceramic materials

-High-temperature operation as high as $1000^{\circ} \mathrm{C}$ which might limit use of less-costly materials

-Need to maintain high-temperature (i.e. thermal management)

- Cost of fabrication

-High-temperatures, the perception which negatively influences automotive customers and prevents acceptance

The critical limitation is the current, long start-up times, generally many minutes to hours. However, the state-of-the-art SOFC development has not directly addressed this issue because current applications are 
directed to stationary, electrical power generation. The long, start-up times of current SOFC stacks has significantly impacted their consideration for use as a power source for automotive applications.

\subsection{Solid State Devices}

Another broad class of energy conversion devices that has the potential to be used as a prime mover is solid-state devices, which produce direct current upon external excitation through light or heat. There are two types of solid-state devices considered here: thermoelectric systems and thermophotovoltaic systems.

\subsubsection{Thermoelectric Systems}

\section{Introduction}

This concept consists of a thermoelectric device that is able to convert a portion of the heat flux traveling through the device, directly into direct current (DC) electrical power. The general principle behind this direct energy conversion is the same as a thermocouple. In fact these devices are composed of units consisting of many thermocouples arranged electrically in series and thermally in parallel to produce DC power at a reasonable voltage. Such a thermoelectric system could be considered to be analogous to the prime mover in combination with the alternator of a conventional gen-set (although the alternator produces AC power).

\section{Application of technology}

The only known commercial application of this technology specifically for electrical power generation is to meet electrical in needs in very remote areas, which have a fuel supply (usually natural gas) and will seldom be attended by people. A small amount of power can be generated by an essentially unattended device. Maintenance intervals as long as 6 months may be possible. This technology may also be applied where heat is being generated for another purpose and a small amount of power is needed. An example would be a water heater, which needs a very small amount of power to run an air fan and/or a water pump. Weight and volume are not much of a concern for these applications.

\section{Description of requirements and performance}

Thermoelectric devices usually are based on modules, which are often relatively thin rectangular tile-like structures, which incorporate many thermocouples (electrically in series, thermally in parallel). One surface of a thermoelectric module would be heated and the other cooled to optimize the temperature gradient. For one particular type of unit examined (reference), the hot surface should be about $230 \mathrm{C}$ (450 F) and the cool side about $30 \mathrm{C}(85 \mathrm{~F})$ to get maximum power output. Another unit specified a hot surface temperature of $1000 \mathrm{C}$ and $140 \mathrm{C}$ for the cooled surface. Designs for other temperature are also feasible. Conversion of heat to electricity can apparently take place with about a 4-7\% efficiency (electrical power output/heat flux through the device) under relatively ideal conditions.

A practical thermoelectric based power unit may require enough parasitic devices to make the concept essentially unworkable. A unit may require some sort of forced-air cooling system, either using a fan to directly cool fins on the "cold" side of the thermoelectric modules or to cool the liquid flowing through a heat exchanger assuming a circulating liquid cooling loop is employed. Other requirements would include a blower for combustion air and fuel pump for a pressurized fuel system feeding the combustion chamber, which heats the hot-side surfaces of the device. A battery and hot-surface type fuel igniter would be needed. A DC to AC power converter system would also be needed. The air fan (or fans), fuel pump, water pump (if needed) and fuel igniter with battery would all reduce the system efficiency by parasitic load. An overall efficiency of $3 \%$ may be quite difficult to achieve for even a well-designed system. 
Commercial (Global Thermoelectric Generators, Inc.) units burning natural gas or propane for remote power are available with manufacturer's reported efficiencies of about 2.3-2.6\%. These devices burn natural gas or propane, and use a natural convection cooling system. They are designed to be fed pressurized gaseous fuel, and the combustion air apparently is drawn into the combustion zone by induction. The only parasitic load appears to be the spark ignition system. The reported power-to-weight values are $1-5 \mathrm{~W} / \mathrm{kg}$ for these commercially available units. No fuel system is included in this weight because it is assumed a supply of pressurized gaseous fuel is available.

A military thermoelectric-based generator unit would require ruggedization, fuel and fuel storage, a fuel pump and fueling system, and a forced air combustion air system. Volumetric and ruggedization considerations would likely dictate an active cooling system rather than a free convection system. Power electronics for conversion from DC to AC power would be included also. It is clearly seen these additions or changes would add weight and parasitic losses. Even a unit based on advanced technology would optimistically be limited to an efficiency of $3 \%$ and a power-to-weight ratio of $5 \mathrm{~W} / \mathrm{kg}$.

Due to the low power-to-weight ratio, this technology is unsuitable as a main power source for the type of expeditionary gen-sets under consideration in this study. This technology was also examined as a possible method to extract electrical power from the waste heat (most likely the exhaust stream) of another powering technology. Unfortunately, the very high weight alone makes it unsuitable for this application as well. Considering added complexity, volume and cost solidifies the conclusion that other methods of improving power-to-weight and power-to-volume should be considered.

Advantages: Low noise and vibration, low emissions, few moving parts,

Disadvantages: Extremely low fuel efficiency, prohibitively low power-to-weight, low power-to-volume ratio, use of exotic materials, high thermal signature, little commercial use of technology.

Comments: Technology is unacceptable for application of interest, and too heavy for combined cycle utilization. Extent of development expected in 5-10 years: Development for space power and selfpowered water heaters or furnaces.

\section{References}

John C. Bass et al., "Design and Test of a Prototype 1 kW Generator for Diesel Engines, ” HZ043097-1, (Hi-Z Technology, Inc.) final report to ORNL under subcontract 86X-SK-530C, June 1997.

Teledyne Energy Systems, “Evaluation of Novel Waste Heat recovery Concepts for Heavy-Duty Diesel Engines,” TES-191C-16, report to ORNL under Subcontract 86X-SD191C, Feb. 1991.

Hi-Z Technology, Inc. San Die go CA, Website: http://www.hi-z.com.

Global Thermoelectric, Inc. Calgary, Alberta Canada, Website: http://www.globalte.com/.

\subsubsection{Thermophotovoltaic Systems}

\section{Introduction}

A thermophotovoltaic (TPV) cell converts (heat in the form of) infrared (IR) light directly into DC electric power. TPV cells are very similar to solar cells, although they are optimized for conversion of longer wave radiation. A TPV system would include a burner system that heats a material designed to preferentially emit IR radiation in a certain wavelength band. Matched to this emitter would be the TPV cells that are designed to convert this wavelength band of IR radiation into electricity. Normally, the TPV cells need some sort of active cooling to keep them near a temperature for best conversion of radiant 
energy to electricity. Like the thermoelectric system, the TPV system would be analogous to the prime mover in combination with the alternator of a conventional gen-set.

\section{Application of technology}

This technology has a similar use to thermoelectric technology. If a device uses combustion for a purpose such as heating, then TPV can be used to produce a small amount of power. An example is the commercial application of TPV in a $7 \mathrm{~kW}$ heat output propane stove for people living "off-grid," that is in a place with no electric service. About $100 \mathrm{~W}$ of power is generated for charging batteries or some other purpose. A self-powered furnace is also a planned commercial product. Electricity is generated to run the air blowers so the furnace will operate during electrical service interruptions. This technology is also considered for various military and space power devices to generate power in remote areas or for selfpowered combustion devices.

\section{Description of requirements and performance}

The efficient production of IR radiation requires an IR emitter material be heated to temperature of 1100$1250 \mathrm{C}(2000-2300 \mathrm{~F})$ or higher. A typical system configuration would be to use an emitter shaped into a tube that is heated (by combustion of a fuel) on the inside. The photocell is arranged in a larger cylinder shape surrounding the emitter. Mirrored surfaces can be used to reflect radiant energy away from end walls or other places where the energy would be wasted. A method of cooling the photocell is generally used because of a significant drop in conversion efficiency at high temperatures. The combustion system would require a high efficiency recuperator to attain any reasonable system efficiency.

Other requirements that could involve electrical parasitic loads would include blowers for combustion air and cooling air, a cooling water (or other fluid) pump if needed, a fuel pump, and the battery powered hot-surface type fuel igniter. The photocells will require a forced air finned heat removal system or a water-to-air heat exchanger system. A DC to AC power converter system would also be needed to complete the electric conversion.

Conversion efficiencies of 7-12\% have been reported for the heat to electricity conversions portion of the system, and higher efficiencies may be possible with technological advancements. However the parasitic loads mentioned will reduce the efficiency significantly, in some cases by a factor of 2 . A TPV based power unit could optimistically be designed to have a power-to-weight ratio in the range of 5-15 W/kg using propane or natural gas. These power-to-weight figures do not include weight for ruggedization for military use, fuel, fuel storage, or the conversion package for DC to AC power. It is likely that diesel fuel firing will require more maintenance due to fouling or sooting than gaseous fuels. A practical unit for military use would optimistically achieve about 6-8\% efficiency and a power density of 3-10 W/kg, which is not competitive with current military gen-sets (> 30\% efficiency, 12-33 W/kg).

Due to the low power-to-weight ratio and low efficiency this technology is unsuitable as a main power source for the type of expeditionary gen-sets under consideration in this study. This technology was also examined as a possible method to extract electrical power from the waste heat (most likely the exhaust stream) of another powering technology. Unfortunately, the high weight and volume, and the need for a high temperature-radiating source makes it unsuitable for this application as well.

Advantages: Low noise and vibration, few moving parts,

Disadvantages: Very low fuel efficiency, prohibitively low power-to-weight, low power-to-volume ratio, requires exotic materials, high thermal signature, high cost, little commercial use of technology, no experience with diesel fuel combustion. 
Comments: Technology is unacceptable for application of interest and too heavy for combined cycle applications. Extent of development expected in 5-10 years: Development for space power and selfpowered water heaters, stoves and furnaces.

\section{References}

Webpages for TPV research performed at the Vehicle Research Institute at Western Washington University: http://vri.etec.wwu.edu/tpv.htm. A number of research papers concerning TPV are available and are informative.

Personal communication with Dr. Michael Seal, Director Vehicle Research Institute, Western Washington University, Bellingham WA.

Website for JX Crystals, Inc., Issaquah, WA: http://www.jxcrystals.com/. Website for Essential Research, Inc., Cleveland, OH: http://www.er.com/. Website for Thermophotovoltaics (TPV) Home Page: http://www.tpv.org/.

\subsection{EVALUATION OF PRIME MOVERS (ENGINE SCORES)}

The following matrices represent our evaluation of the various prime movers that warrant further consideration for use in a power generation system for expeditionary forces. The prime movers are evaluated at the four power levels of most interest to the USMC: $1,5,15$, and $30 \mathrm{~kW}$. It should be noted that these engines do not necessarily scale well outside these size ranges so the scores may not be applicable to other power levels. The scores range from 1 (low) to 10 (high) and are as consistent as possible in contrasting different prime movers and different power levels. The scalability of the engine across the power range of interest is indicated by the variation in the scores. These scores were determined without consideration of the relative importance or merit of these attributes and are as close as possible to an unbiased appraisal of the expected performance of these prime movers in these areas. Plots and a more detail analysis of the engine scores are included in Appendix 1 (Engine Scores).

Table 5.1 Stirling Cycle Engine Scores

\begin{tabular}{|l|c|c|c|c|}
\hline Attributes & $\mathbf{1 ~ k W}$ & $\mathbf{5 ~ k W}$ & $\mathbf{1 5} \mathbf{~ k W}$ & $\mathbf{3 0} \mathbf{k W}$ \\
\hline 1. High Thermal Efficiency & 6 & 6 & 7 & 7 \\
\hline 2. Low Weight & 4 & 5 & 5 & 5 \\
\hline 3. Low Volume & 5 & 5 & 5 & 5 \\
\hline 4. Low acoustic signature & 5 & 5 & 5 & 5 \\
\hline 5. Low EM signature & 5 & 5 & 5 & 5 \\
\hline 6. Low IR signature & 7 & 7 & 8 & 8 \\
\hline 7. Technical Maturity & 5 & 6 & 8 & 8 \\
\hline 8. Low Cost & 3 & 3 & 3 & 3 \\
\hline 9. Partial Load Operation & 5 & 6 & 7 & 7 \\
\hline 10. Low Emissions & 7 & 8 & 9 & 9 \\
\hline 11. Easy to Use & 8 & 8 & 8 & 8 \\
\hline 12. High Ruggedness/durability & 8 & 8 & 8 & 8 \\
\hline 13. Low maintenance requirements & 5 & 5 & 5 & 5 \\
\hline 14. High Reliability & 4 & 4 & 4 & 4 \\
\hline
\end{tabular}


Table 5.2 Rankine Cycle Engine Scores

\begin{tabular}{|l|c|c|c|c|}
\hline Attributes & $\mathbf{1 ~ k W}$ & $\mathbf{5 ~ k W}$ & $\mathbf{1 5} \mathbf{k W}$ & $\mathbf{3 0} \mathbf{k W}$ \\
\hline 1. High Thermal Efficiency & 4 & 5 & 5 & 5 \\
\hline 2. Low Weight & 4 & 5 & 6 & 6 \\
\hline 3. Low Volume & 3 & 3 & 3 & 3 \\
\hline 4. Low acoustic signature & 4 & 4 & 4 & 4 \\
\hline 5. Low EM signature & 5 & 5 & 5 & 5 \\
\hline 6. Low IR signature & 5 & 5 & 6 & 6 \\
\hline 7. Technical Maturity & 4 & 5 & 8 & 9 \\
\hline 8. Low Cost & 2 & 2 & 3 & 3 \\
\hline 9. Partial Load Operation & 5 & 5 & 6 & 6 \\
\hline 10. Low Emissions & 7 & 8 & 9 & 9 \\
\hline 11. Easy to Use & 5 & 5 & 5 & 5 \\
\hline 12. High Ruggedness/durability & 7 & 7 & 7 & 7 \\
\hline 13. Low maintenance requirements & 3 & 3 & 3 & 3 \\
\hline 14. High Reliability & 4 & 4 & 4 & 4 \\
\hline
\end{tabular}

Table 5.3 Open Brayton Cycle Engine Scores

\begin{tabular}{|l|c|c|c|c|}
\hline Attributes & $\mathbf{1 ~ k W}$ & $\mathbf{5 ~ k W}$ & $\mathbf{1 5} \mathbf{~ W W}$ & $\mathbf{3 0} \mathbf{~ k W}$ \\
\hline 1. High Thermal Efficiency & 4 & 5 & 6 & 6 \\
\hline 2. Low Weight & 6 & 7 & 8 & 8 \\
\hline 3. Low Volume & 8 & 8 & 9 & 9 \\
\hline 4. Low acoustic signature & 4 & 4 & 4 & 4 \\
\hline 5. Low EM signature & 5 & 5 & 5 & 5 \\
\hline 6. Low IR signature & 7 & 7 & 8 & 8 \\
\hline 7. Technic al Maturity & 5 & 6 & 9 & 9 \\
\hline 8. Low Cost & 3 & 3 & 4 & 4 \\
\hline 9. Partial Load Operation & 6 & 7 & 8 & 8 \\
\hline 10. Low Emissions & 6 & 6 & 7 & 7 \\
\hline 11. Easy to Use & 8 & 8 & 8 & 8 \\
\hline 12. High Ruggedness/durability & 8 & 8 & 8 & 8 \\
\hline 13. Low maintenance requirements & 5 & 6 & 8 & 8 \\
\hline 14. High Reliability & 8 & 8 & 9 & 9 \\
\hline
\end{tabular}


Table 5.4 Closed Brayton Cycle Engine Scores

\begin{tabular}{|l|c|c|c|c|}
\hline Attributes & $\mathbf{1 ~ k W}$ & $\mathbf{5 ~ k W}$ & $\mathbf{1 5} \mathbf{~ W W}$ & $\mathbf{3 0} \mathbf{k W}$ \\
\hline 1. High Thermal Efficiency & 7 & 8 & 9 & 9 \\
\hline 2. Low Weight & 5 & 6 & 7 & 7 \\
\hline 3. Low Volume & 5 & 5 & 5 & 5 \\
\hline 4. Low acoustic signature & 5 & 5 & 5 & 5 \\
\hline 5. Low EM signature & 5 & 5 & 5 & 5 \\
\hline 6. Low IR signature & 7 & 7 & 8 & 8 \\
\hline 7. Technical Maturity & 3 & 4 & 6 & 8 \\
\hline 8. Low Cost & 3 & 3 & 4 & 4 \\
\hline 9. Partial Load Operation & 7 & 8 & 9 & 9 \\
\hline 10. Low Emissions & 7 & 8 & 9 & 9 \\
\hline 11. Easy to Use & 8 & 8 & 8 & 8 \\
\hline 12. High Ruggedness/durability & 8 & 8 & 8 & 8 \\
\hline 13. Low maintenance requirements & 5 & 6 & 8 & 8 \\
\hline 14. High Reliability & 8 & 8 & 9 & 9 \\
\hline
\end{tabular}

Table 5.5 Active Working Fluid Cycle

\begin{tabular}{|l|c|c|c|c|}
\hline Attributes & $\mathbf{1 ~ k W}$ & $\mathbf{5 ~ k W}$ & $\mathbf{1 5} \mathbf{~ k W}$ & $\mathbf{3 0} \mathbf{~ k W}$ \\
\hline 1. High Thermal Efficiency & 7 & 8 & 9 & 9 \\
\hline 2. Low Weight & 6 & 7 & 8 & 8 \\
\hline 3. Low Volume & 8 & 8 & 8 & 8 \\
\hline 4. Low Acoustic Signature & 5 & 5 & 5 & 5 \\
\hline 5. Low EM Signature & 5 & 5 & 5 & 5 \\
\hline 6. Low IR Signature & 7 & 7 & 8 & 8 \\
\hline 7. Technical Maturity & 2 & 2 & 2 & 2 \\
\hline 8. Cost & 2 & 2 & 3 & 3 \\
\hline 9. Partial Load Operation & 7 & 8 & 9 & 9 \\
\hline 10. Emissions & 7 & 8 & 9 & 9 \\
\hline 11. Ease of use & 8 & 8 & 8 & 8 \\
\hline 12. Ruggedness & 8 & 8 & 8 & 8 \\
\hline 13. Maintenance & 4 & 5 & 7 & 7 \\
\hline 14. Reliability & 7 & 7 & 8 & 8 \\
\hline
\end{tabular}


Table 5.6 Atkinson Cycle Engine Scores

\begin{tabular}{|l|c|c|c|c|}
\hline Attributes & $\mathbf{1 ~ k W}$ & $\mathbf{5 ~ k W}$ & $\mathbf{1 5} \mathbf{~ W W}$ & $\mathbf{3 0} \mathbf{~ k W}$ \\
\hline 1. High Thermal Efficiency & 6 & 7 & 8 & 8 \\
\hline 2. Low Weight & 7 & 8 & 8 & 8 \\
\hline 3. Low Volume & 8 & 8 & 9 & 9 \\
\hline 4. Low Acoustic Signature & 5 & 5 & 5 & 5 \\
\hline 5. Low EM Signature & 5 & 5 & 5 & 5 \\
\hline 6. Low IR Signature & 7 & 7 & 8 & 8 \\
\hline 7. Technical Maturity & 4 & 4 & 4 & 4 \\
\hline 8. Cost & 3 & 3 & 4 & 4 \\
\hline 9. Partial Load Operation & 7 & 8 & 9 & 9 \\
\hline 10. Emissions & 6 & 6 & 7 & 7 \\
\hline 11. Ease of use & 8 & 8 & 8 & 8 \\
\hline 12. Ruggedness & 8 & 8 & 8 & 8 \\
\hline 13. Maintenance & 5 & 6 & 8 & 8 \\
\hline 14. Reliability & 8 & 8 & 9 & 9 \\
\hline
\end{tabular}

Table 5.7 Reciprocating Diesel Cycle Engine Scores

\begin{tabular}{|l|c|c|c|c|}
\hline Attributes & $\mathbf{1 ~ k W}$ & $\mathbf{5 ~ k W}$ & $\mathbf{1 5} \mathbf{~ k W}$ & $\mathbf{3 0} \mathbf{~ k W}$ \\
\hline 1. High Thermal Efficiency & 7 & 7 & 8 & 8 \\
\hline 2. Low Weight & 4 & 5 & 6 & 6 \\
\hline 3. Low Volume & 6 & 6 & 7 & 7 \\
\hline 4. Low acoustic signature & 2 & 2 & 3 & 3 \\
\hline 5. Low EM signature & 5 & 5 & 5 & 5 \\
\hline 6. Low IR signature & 7 & 7 & 8 & 8 \\
\hline 7. Technical Maturity & 10 & 10 & 10 & 10 \\
\hline 8. Low Cost & 8 & 8 & 8 & 8 \\
\hline 9. Partial Load Operation & 7 & 8 & 9 & 9 \\
\hline 10. Low Emissions & 5 & 5 & 6 & 6 \\
\hline 11. Easy to Use & 8 & 8 & 8 & 8 \\
\hline 12. High Ruggedness/durability & 9 & 9 & 9 & 9 \\
\hline 13. Low maintenance requirements & 6 & 6 & 6 & 6 \\
\hline 14. High Reliability & 7 & 7 & 8 & 8 \\
\hline
\end{tabular}


Table 5.8 2-Stroke Reciprocating Compression Ignition Engine Scores

\begin{tabular}{|l|c|c|c|c|}
\hline Attributes & $\mathbf{1 ~ k W}$ & $\mathbf{5 ~ k W}$ & $\mathbf{1 5} \mathbf{~ k W}$ & $\mathbf{3 0} \mathbf{k W}$ \\
\hline 1. High Thermal Efficiency & 6 & 6 & 7 & 8 \\
\hline 2. Low Weight & 7 & 7 & 7 & 7 \\
\hline 3. Low Volume & 7 & 7 & 8 & 8 \\
\hline 4. Low acoustic signature & 2 & 2 & 3 & 3 \\
\hline 5. Low EM signature & 3 & 3 & 3 & 3 \\
\hline 6. Low IR signature & 7 & 7 & 7 & 8 \\
\hline 7. Technical Maturity & 3 & 4 & 4 & $7 *$ \\
\hline 8. Low Cost & 5 & 5 & 5 & 5 \\
\hline 9. Partial Load Operation & 7 & 8 & 9 & 9 \\
\hline 10. Low Emissions & 4 & 4 & 4 & 4 \\
\hline 11. Easy to Use & 6 & 6 & 6 & 7 \\
\hline 12. High Ruggedness/durability & 7 & 7 & 7 & 7 \\
\hline 13. Low maintenance requirements & 4 & 4 & 4 & 4 \\
\hline 14. High Reliability & 5 & 6 & 6 & 6 \\
\hline
\end{tabular}

* Based on Daihatsu engine.

Table 5.9 Rotary Compression Ignition Engine Scores

\begin{tabular}{|l|c|c|c|c|}
\hline Attributes & $\mathbf{1 ~ k W}$ & $\mathbf{5 ~ k W}$ & $\mathbf{1 5} \mathbf{~ W W}$ & $\mathbf{3 0} \mathbf{k W}$ \\
\hline 1. High Thermal Efficiency & 3 & 3 & 3 & 3 \\
\hline 2. Low Weight & 7 & 7 & 8 & 8 \\
\hline 3. Low Volume & 7 & 7 & 8 & 8 \\
\hline 4. Low acoustic signature & 5 & 5 & 5 & 5 \\
\hline 5. Low EM signature & 5 & 5 & 5 & 5 \\
\hline 6. Low IR signature & 4 & 4 & 4 & 4 \\
\hline 7. Technical Maturity & 3 & 4 & 5 & 5 \\
\hline 8. Low Cost & 5 & 5 & 5 & 5 \\
\hline 9. Partial Load Operation & 7 & 7 & 7 & 7 \\
\hline 10. Low Emissions & 4 & 4 & 4 & 4 \\
\hline 11. Easy to Use & 7 & 7 & 7 & 7 \\
\hline 12. High Ruggedness/durability & 8 & 8 & 8 & 8 \\
\hline 13. Low maintenance requirements & 5 & 5 & 5 & 5 \\
\hline 14. High Reliability & 4 & 4 & 5 & 5 \\
\hline
\end{tabular}


Table 5.10 Otto Cycle Engine Scores (includes rotary 4-stroke and reciprocating 2-stroke spark ignition)

\begin{tabular}{|l|c|c|c|c|}
\hline Attributes & $\mathbf{1 ~ k W}$ & $\mathbf{5 ~ k W}$ & $\mathbf{1 5} \mathbf{~ k W}$ & $\mathbf{3 0} \mathbf{k W}$ \\
\hline 1. High Thermal Efficiency & 4 & 4 & 5 & 5 \\
\hline 2. Low Weight & 7 & 7 & 8 & 8 \\
\hline 3. Low Volume & 7 & 7 & 8 & 8 \\
\hline 4. Low acoustic signature & 4 & 4 & 4 & 4 \\
\hline 5. Low EM signature & 3 & 3 & 3 & 3 \\
\hline 6. Low IR signature & 3 & 3 & 3 & 3 \\
\hline 7. Technical Maturity & 3 & 4 & 5 & 5 \\
\hline 8. Low Cost & 5 & 5 & 5 & 5 \\
\hline 9. Partial Load Operation & 7 & 7 & 7 & 8 \\
\hline 10. Low Emissions & 3 & 3 & 3 & 3 \\
\hline 11. Easy to Use & 6 & 6 & 6 & 6 \\
\hline 12. High Ruggedness/durability & 7 & 7 & 7 & 7 \\
\hline 13. Low maintenance requirements & 4 & 4 & 4 & 4 \\
\hline 14. High Reliability & 4 & 4 & 4 & 4 \\
\hline
\end{tabular}

Table 5.11 PEM Fuel Cell Scores

\begin{tabular}{|l|c|c|c|c|}
\hline Attributes & $\mathbf{1 ~ k W}$ & $\mathbf{5 ~ k W}$ & $\mathbf{1 5} \mathbf{~ W W}$ & $\mathbf{3 0} \mathbf{k W}$ \\
\hline 1. High Thermal Efficiency & 6 & 6 & 7 & 7 \\
\hline 2. Low Weight & 3 & 4 & 4 & 4 \\
\hline 3. Low Volume & 3 & 4 & 4 & 5 \\
\hline 4. Low acoustic signature & 8 & 8 & 9 & 9 \\
\hline 5. Low EM signature & 8 & 8 & 8 & 8 \\
\hline 6. Low IR signature & 7 & 7 & 7 & 7 \\
\hline 7. Technical Maturity & 4 & 4 & 4 & 4 \\
\hline 8. Low Cost & 3 & 3 & 3 & 3 \\
\hline 9. Partial Load Operation & 8 & 8 & 8 & 8 \\
\hline 10. Low Emissions & 8 & 8 & 9 & 9 \\
\hline 11. Easy to Use & 7 & 7 & 7 & 7 \\
\hline 12. High Ruggedness/durability & 6 & 6 & 6 & 6 \\
\hline 13. Low maintenance requirements & 5 & 5 & 5 & 5 \\
\hline 14. High Reliability & 5 & 5 & 5 & 5 \\
\hline
\end{tabular}


Table 5.12 SOFC Fuel Cell Scores

\begin{tabular}{|l|c|c|c|c|}
\hline Attributes & $\mathbf{1 ~ k W}$ & $\mathbf{5 ~ k W}$ & $\mathbf{1 5} \mathbf{k W}$ & $\mathbf{3 0} \mathbf{k W}$ \\
\hline 1. High Thermal Efficiency & 9 & 9 & 9 & 9 \\
\hline 2. Low Weight & 3 & 4 & 4 & 4 \\
\hline 3. Low Volume & 6 & 8 & 8 & 8 \\
\hline 4. Low acoustic signature & 8 & 8 & 9 & 9 \\
\hline 5. Low EM signature & 8 & 8 & 8 & 8 \\
\hline 6. Low IR signature & 7 & 7 & 7 & 7 \\
\hline 7. Technical Maturity & 3 & 3 & 3 & 3 \\
\hline 8. Low Cost & 3 & 3 & 3 & 3 \\
\hline 9. Partial Load Operation & 8 & 8 & 8 & 8 \\
\hline 10. Low Emissions & 8 & 8 & 9 & 9 \\
\hline 11. Easy to Use & 8 & 8 & 8 & 8 \\
\hline 12. High Ruggedness/durability & 7 & 7 & 7 & 7 \\
\hline 13. Low maintenance requirements & 7 & 7 & 7 & 7 \\
\hline 14. High Reliability & 6 & 6 & 6 & 6 \\
\hline
\end{tabular}

Table 5.13 Thermoelectric Scores

\begin{tabular}{|l|c|c|c|c|}
\hline Attributes & $\mathbf{1 ~ k W}$ & $\mathbf{5 ~ k W}$ & $\mathbf{1 5} \mathbf{~ k W}$ & $\mathbf{3 0} \mathbf{k W}$ \\
\hline 1. High Thermal Efficiency & 1 & 1 & 1 & 1 \\
\hline 2. Low Weight & 1 & 1 & 2 & 2 \\
\hline 3. Low Volume & 3 & 3 & 3 & 3 \\
\hline 4. Low acoustic signature & 9 & 9 & 9 & 9 \\
\hline 5. Low EM signature & 9 & 9 & 9 & 9 \\
\hline 6. Low IR signature & 1 & 1 & 1 & 1 \\
\hline 7. Technical Maturity & 5 & 5 & 5 & 5 \\
\hline 8. Low Cost & 2 & 2 & 1 & 1 \\
\hline 9. Partial Load Operation & 8 & 8 & 8 & 8 \\
\hline 10. Low Emissions & 7 & 8 & 9 & 9 \\
\hline 11. Easy to Use & 9 & 9 & 9 & 9 \\
\hline 12. High Ruggedness/durability & 8 & 8 & 8 & 8 \\
\hline 13. Low maintenance requirements & 5 & 5 & 5 & 6 \\
\hline 14. High Reliability & 7 & 7 & 7 & 7 \\
\hline
\end{tabular}


Table 5.14 Thermophotovoltaic Scores

\begin{tabular}{|l|c|c|c|c|}
\hline Attributes & $\mathbf{1 ~ k W}$ & $\mathbf{5 ~ k W}$ & $\mathbf{1 5} \mathbf{~} \mathbf{W}$ & $\mathbf{3 0} \mathbf{~ k W}$ \\
\hline 1. High Thermal Efficiency & 2 & 2 & 2 & 2 \\
\hline 2. Low Weight & 2 & 2 & 2 & 2 \\
\hline 3. Low Volume & 3 & 3 & 3 & 3 \\
\hline 4. Low acoustic signature & 9 & 9 & 9 & 9 \\
\hline 5. Low EM signature & 9 & 9 & 9 & 9 \\
\hline 6. Low IR signature & 2 & 2 & 2 & 2 \\
\hline 7. Technical Maturity & 4 & 4 & 4 & 4 \\
\hline 8. Low Cost & 1 & 1 & 1 & 1 \\
\hline 9. Partial Load Operation & 8 & 8 & 8 & 8 \\
\hline 10. Low Emissions & 7 & 8 & 9 & 9 \\
\hline 11. Easy to Use & 9 & 9 & 9 & 9 \\
\hline 12. High Ruggedness/durability & 5 & 5 & 5 & 5 \\
\hline 13. Low maintenance requirements & 4 & 4 & 4 & 4 \\
\hline 14. High Reliability & 4 & 4 & 4 & 4 \\
\hline
\end{tabular}

\subsection{WEIGHT FACTORS DETERMINED BY USMC}

The following weight factors were input to ORNL by the USMC and to assess the relative importance of each attribute so that the prime mover best suitable for use in expeditionary forces could be determined. A plot of these weight factors is shown in Appendix 1.

Table 6.1 USMC Weight Factors for Engine Attributes

\begin{tabular}{|l|c|}
\hline Attributes & Weight \\
\hline 1. High Thermal Efficiency & 4.5 \\
\hline 2. Low Weight & 9.0 \\
\hline 3. Low Volume & 9.0 \\
\hline 4. Low acoustic signature & 5.5 \\
\hline 5. Low EM signature & 2.0 \\
\hline 6. Low IR signature & 3.0 \\
\hline 7. Technical Maturity & 2.5 \\
\hline 8. Low Cost & 1.0 \\
\hline 9. Partial Load Operation & 6.5 \\
\hline 10. Low Emissions & 3.0 \\
\hline 11. Easy to Use & 5.0 \\
\hline 12. High Ruggedness/durability & 5.5 \\
\hline 13. Low maintenance requirements & 5.5 \\
\hline 14. High Reliability & 8.0 \\
\hline
\end{tabular}

The weight factors tend to fall in three groupings: high importance (6-10), medium importance (4-6), and lower importance (1-4). According to the USMC weightings, four attributes are of high importance for the prime movers in expeditionary generators sets (weight, volume, reliability, and load following capability). 


\subsection{KEPNER/TREGOE (K/T) ANALYSIS}

The weight factors and engine scores were used in a Kepner/Tregoe $(\mathrm{K} / \mathrm{T})$ analysis, which is designed to give a fair evaluation of the prime mover most suitable for the USMC application. The results are given below but plots of the results and additional information is included in Appendix 2. We feel the results listed here should be an indicator of the type of engine(s) most likely to produce a gen-set suitable for the USMC expeditionary forces. The engines are listed in the following tables (a separate assessment is done for each power level) with their final $\mathrm{K} / \mathrm{T}$ score from the most suitable to the least suitable for USMC needs. A listing of the prime movers and their weighted scores are in Tables 7.1 - 7.4.

Table 7.1 Weighted Analysis of Prime Movers for $1 \mathrm{~kW}$

\begin{tabular}{|l|c|}
\hline Prime Mover & $\begin{array}{c}\text { Final } \\
\text { Score }\end{array}$ \\
\hline 1. Atkinson & 472.5 \\
\hline 2. Solid Oxide Fuel Cell & 454 \\
\hline 3. AWF Brayton & 445 \\
\hline 4. Open Brayton & 445 \\
\hline 5. Diesel (4-stroke) & 435.5 \\
\hline 6. Closed Brayton & 432.5 \\
\hline 7. Rotary Diesel & 497.5 \\
\hline 8. 2-Stroke Diesel & 391.5 \\
\hline 9. PEM Fuel Cell & 386.5 \\
\hline 10. Stirling & 379 \\
\hline 11. Thermoelectric & 371 \\
\hline 12. Otto & 370.5 \\
\hline 13. TPV & 338 \\
\hline 14. Rankine & 305.5 \\
\hline
\end{tabular}

Table 7.2 Weighted Analysis of Prime Movers for 5 kW

\begin{tabular}{|l|c|}
\hline Prime Mover & $\begin{array}{c}\text { Final } \\
\text { Score }\end{array}$ \\
\hline 1. Atkinson & 498 \\
\hline 2. Solid Oxide Fuel Cell & 481 \\
\hline 3. AWF Brayton & 480 \\
\hline 4. Open Brayton & 473 \\
\hline 5. Closed Brayton & 463.5 \\
\hline 6. Diesel (4-stroke) & 451 \\
\hline 7. 2-Stroke Diesel & 408.5 \\
\hline 8. PEM Fuel Cell & 404.5 \\
\hline 9. Rotary Diesel & 400 \\
\hline 10. Stirling & 400 \\
\hline 11. Thermoelectric & 374 \\
\hline 12. Otto & 373 \\
\hline 13. TPV & 341 \\
\hline 14. Rankine & 324.5 \\
\hline
\end{tabular}


Table 7.3 Weighted Analysis of Prime Movers for 15 kW

\begin{tabular}{|l|c|}
\hline Prime Mover & $\begin{array}{c}\text { Final } \\
\text { Score }\end{array}$ \\
\hline 1. Atkinson & 544 \\
\hline 2. Open Brayton & 535.5 \\
\hline 3. AWF Cycle & 525 \\
\hline 4. Closed Brayton & 514.5 \\
\hline 5. Diesel Engine & 499.5 \\
\hline 6. SOFC & 489.5 \\
\hline 7. 2 Stroke CI & 426 \\
\hline 8. Stirling & 422 \\
\hline 9. Rotary Diesel & 420.5 \\
\hline 10. PEM Fuel Cell & 417.5 \\
\hline 11. Otto & 398 \\
\hline 12. Thermoelectric & 385 \\
\hline 13. Rankine & 354.5 \\
\hline 14. TPV & 344 \\
\hline
\end{tabular}

Table 7.4 Weighted Analysis of Prime Movers for $30 \mathrm{~kW}$

\begin{tabular}{|l|c|}
\hline Prime Mover & $\begin{array}{c}\text { Final } \\
\text { Score }\end{array}$ \\
\hline 1. Atkinson & 544 \\
\hline 2. Open Brayton & 535.5 \\
\hline 3. AWF Cycle & 525 \\
\hline 4. Closed Brayton & 519.5 \\
\hline 5. Diesel Engine & 499.5 \\
\hline 6. SOFC & 489.5 \\
\hline 7. 2 Stroke CI & 454 \\
\hline 8. PEM Fuel Cell & 426.5 \\
\hline 9. Stirling & 422 \\
\hline 10. Rotary Diesel & 420.5 \\
\hline 11. Otto & 404.5 \\
\hline 12. Thermoelectric & 390.5 \\
\hline 13. Rankine & 357 \\
\hline 14. TPV & 344 \\
\hline
\end{tabular}

Examination of the total weighted scores themselves indicates a couple of things. First, the results are scalable in the manner expected with the scores increasing as a function of load level. The scores for the 15 and $30 \mathrm{~kW}$ loads are very similar and $\sim 15 \%$ higher than the scores at the $1 \mathrm{~kW}$ level. Second, the scores are quite close together with no clear-cut choice for the prime mover to power a generator set for expeditionary forces. While the analysis fails to indicate the "perfect" engine for this application, there are several engines that could do as well or better than the standard choice of a diesel engine, which is encouraging.

Not surprising is the fact that the Brayton cycle engines (gas turbines) scored quite high. These engines are known to be very compact and reliable prime movers. It is somewhat surprising that the Atkinson cycle does quite well and scored the highest of all engines considered at all four size ranges. Another 
interesting result is that the SOFC does quite well at the lower power levels. The SOFC is a very scalable prime mover so its score at lower power levels rank it quite high while at higher power levels other prime movers surpass it.

\subsection{INTERPRETATION OF RESULTS}

Several conclusions can be made based on the results so far and are important to understand to better interpret the results. Particular emphasis is given to the interpretation of the $5 \mathrm{~kW}$ level and the need that the USMC has identified for a $5 \mathrm{~kW}$ mobile generator that weighs $150 \mathrm{lb}$ or less.

\subsection{Fuel Consumption and Mission Duration}

The USMC rated "Fuel Economy" as being of moderate importance and on the surface that seems a very reasonable evaluation. However, when considering the mission duration for expeditionary forces, fuel consumption can play a larger role than first thought. Consider a single Marine Expeditionary Unit (MEU) requiring a single mobile $5 \mathrm{~kW}$ gen-set for a mission that stretches for two weeks. Under war-time mission profiles used by the DOD (see Andriulli, Nov. 1999), it is reasonable to assume that the gen-set will be fully loaded for 12 hours/day for that two week stretch for $\sim 840 \mathrm{~kW}-\mathrm{hr}$. Fuel consumption can vary as much as a factor of two between the engines surveyed in this report with the difference approaching $200 \mathrm{~g} / \mathrm{kW}-\mathrm{hr}$ (compare the diesel engine and the rotary CI). That means for the mission duration of two weeks as described, the difference in fuel consumed could be as much as 55 gallons of fuel. If you further assume that re-supply missions would be limited to $150 \mathrm{lb}$, then fuel re-supply would have to occur every three days. An 8-hour fuel supply for an inefficient engine in a $5 \mathrm{~kW}$ gen-set would be about $35 \mathrm{lb}$.

Under mission durations towards the longer projections, fuel consumption clearly can play an important role and warrants further examination. For short missions (3-5 days), the fuel consumption does not really have an impact on the total weight required for the mission. The importance of fuel efficiency, thus, is directly related to the mission duration and logistics of re-supplying fuel.

\subsection{No "Silver Bullets"}

A key point borne out by the data in this survey is that today there is no "silver bullet" engine that simply offers superior performance in all or nearly all attributes. In examining the ratings developed between the engines, no overwhelming winner was found. In addition, if reasonable uncertainty were factored into the scores, the ratings are close enough that the order could change quite a bit. There are clearly some engines that have received a lot of development and are quite mature or well understood, and perform well in many areas. However, no engine was found that dominated all attributes (or even most of them) and all engines perform well in some areas. Furthermore, it seems that based on the scientific foundations previously discussed and in the time frame for expeditionary gen-sets $(\sim 2010)$, no engine is likely to emerge that gives superior performance across the board. It appears that trade-offs will have to be evaluated for this and other applications.

\subsection{Relationship Between Fuel, Prime Mover, and Application}

In our opinion, one of the strongest conclusions out of this effort is that there is an intertwined relationship between the fuel used, the prime mover and the application. In other words, you must consider all aspects of the prime mover and its use rather than just pick and choose a good "engine" and alter the application. The SCEPS engine is a perfect example of a good application for a Rankine engine in that the water-cooling allows a much smaller engine. However, using the Rankine engine in a land- 
based application such as a gen-set, the unique advantages are lost and the engine simply wouldn't be as suitable. Not a "poor" engine but an inconsistent match between the engine and its application.

The use of fuel for USMC expeditionary forces must also be carefully considered as the fuel and engine are so closely tied. In this survey, all engines were assumed to use diesel fuel, which is not the optimum selection for several of the engines, considered and the scores reflected the difficulty. The PEM fuel cell and Otto engine were basically eliminated since they don't burn diesel fuel well. External combustion engines, on the other hand, are inherently multi-fuel compatible so they burn diesel fuel well but could burn other fuels too. If the fuel changed, the engines will need to be re-considered. The primary point is that the relationship between fuelengine-application is one that must be carefully understood and exploited. Unique applications may in fact allow for unique engine choices.

\subsection{Analysis of Engine by Importance of Attributes}

Given that the initial results are less clear-cut than what would be desired, additional interpretation is needed. It is useful to exam the final $\mathrm{K} / \mathrm{T}$ scores to determine how the various attributes influence the final weighted score. The weight factors actually fall into three categories (high importance areas (6-10), medium importance areas (4-6), and lower importance areas (1-4). The weighted K/T scores were determined for each prime mover as a function of the importance level. The weighted scores for the $5 \mathrm{~kW}$ level divided by importance level is listed in Table 8.1. A plot of these results are shown in Appendix 2.

Table 8.1 Weighted Analysis by Importance Levels of Prime Movers for 5 kW

\begin{tabular}{|l|c|c|c|}
\hline Prime Mover & $\begin{array}{c}\text { K/T Score } \\
\text { from High } \\
\text { Importance } \\
\text { Attributes }\end{array}$ & $\begin{array}{c}\text { K/T Score } \\
\text { from } \\
\text { Medium } \\
\text { Importance } \\
\text { Attributes }\end{array}$ & $\begin{array}{c}\text { K/T Score } \\
\text { from Low } \\
\text { Importance } \\
\text { Attributes }\end{array}$ \\
\hline 13. Atkinson & 260 & 176 & 62 \\
\hline 3. Open Brayton & 244.5 & 161.5 & 67 \\
\hline 12. AWF Cycle & 243 & 175 & 62 \\
\hline 14. 2 Stroke CI & 226 & 128.5 & 54 \\
\hline 4. Closed Brayton & 215 & 180.5 & 68 \\
\hline 11. SOFC & 208 & 201.5 & 71.5 \\
\hline 5. Diesel Engine & 207 & 165 & 79 \\
\hline 6. Rotary Diesel & 203.5 & 147.5 & 49 \\
\hline 8. Otto & 203.5 & 135 & 39 \\
\hline 7. PEM Fuel Cell & 164 & 166.5 & 74 \\
\hline 1. Stirling & 161 & 166 & 73 \\
\hline 9. Thermoelectric & 144 & 170.5 & 59.5 \\
\hline 2. Rankine & 136.5 & 124.5 & 63.5 \\
\hline 10. TPV & 129 & 153 & 59 \\
\hline
\end{tabular}


The analysis as a function of importance level reveals that several of the prime movers that scored well overall that did not score so well when only considering the attributes most important to the USMC. In other words, since no "silver bullet" engine exists and all engines have positive attributes, the overall weighted scores tended to even out. Some prime movers received most of its points from lower and medium importance areas. Since weight, volume and reliability are clearly the most important attributes to consider, the scores from the high importance areas are useful in recommending further action for the USMC.

\section{References:}

Andriulli, J. B., et. al., "Advanced Power Generation Systems for the $21^{\text {st }}$ Century, Market Survey and Recommendations for a Design Philosophy" ORNL/TM-1999/213, Prepared for the Communication and Electronics Command - Research, Development, \& Engineering Center, Fort Belvoir, VA, Oak Ridge National Laboratory, Oak Ridge, TN, November, 1999.

\subsection{CONCLUSIONS \& RECOMMENDATIONS}

The conclusions of this effort and the recommendations on future prime movers for USMC expeditionary forces are given in this section. It is important that the recommendations be considered in context of this study so the primary conclusions and observations of the report are re-stated here.

\subsection{Conclusions \& Observations}

- The time frame for deployment of OMFTS (2010) will force the selection of a relatively mature prime mover or the rapid development of less mature technologies. Research to find new choices not yet "on the scene" appears unlikely to produce a suitable unit in sufficient time.

- The scalability of the prime movers varies widely and is a major driver behind the differing recommendations between the higher and lower load levels.

- No single prime mover exists that is clearly superior in all (or even most) areas (i.e., no "silver bullet" exists).

- The relationship between the fuel, prime mover, and application is intertwined and must be understood. If the fuel or applications changes, the most suitable prime mover likely will be different as well.

- The expeditionary forces represent a unique application for gen-sets, which must be treated uniquely.

- The importance of fuel economy needs to be reconsidered. Mission durations of two weeks are possible, which would have high fuel re-supply requirements if inefficient engines were used.

- The goal of developing a unit capable of $5 \mathrm{~kW}$ that weighs less than $150 \mathrm{lb}$ is clearly ambitious but can be achieved with some risks. Tradeoffs will certainly have to be made.

\subsection{Summary of Candidate Prime Movers}

The following prime movers are potential candidates for a prime mover for powering a generator set for expeditionary forces. The prime movers described below are the most likely to meet the USMC objectives. 


\subsubsection{Atkinson cycle}

The Atkinson cycle engine as proposed by Wilson (TurbX Engines, Inc.) is an interesting engine that warrants further consideration. It scores not only the highest overall at all four load levels, it scores highest when only considering the attributes most important to the USMC. Its primary drawback is that it is not mature. ORNL review of the underlying thermodynamics reveal that it is credible and should offer unique advantages. Interestingly, this cycle also offers very good fuel economy and load following. Overall we feel that this engine may produce the most satisfactory prime mover for expeditionary forces but it will require some sustained development. Key potential show-stoppers can be investigated (manufacturability, unavoidable heat losses, etc) before a focussed development begins.

\subsubsection{Brayton cycles (Open, Closed, AWF)}

The Brayton based prime movers all scored close together and appear possible to produce a unit that meets the required goals. We feel that the closed and AWF variations of the Brayton cycle should be developed after the open Brayton. The closed cycle can offer significant efficiency improvements but at a cost of additional complexity and size. Gas turbines are well understood and being developed for smaller power levels. Developments of this technology should be watched closely. Adaptation of turbines at 1-5 $\mathrm{kW}$ should be feasible but the fuel economy is unknown at this time.

\subsubsection{Two Stroke Diesel}

The 2-stroke diesel developed for Unmanned Aerial Vehicle (UAV) appears to be a candidate engine that can meet the weight requirements. It is our opinion that this engine could satisfy the weight goal with the least development of any engine. The most significant barriers will be meeting EPA emission requirements and reasonable noise levels.

\subsubsection{Solid Oxide Fuel Cell (SOFC)}

Solid Oxide Fuel Cells could potentially meet the weight goal required and offer several attractive features but seem too immature a technology to be developed for this application without a lot of research and development. SOFCs are unique in that they are compact but heavy. The balance-of-plant, long start up times, and reformer issues will have to be addressed before they stand a chance of being acceptable in the timeframe desired.

\subsubsection{Four Stroke Diesel Engine}

The 4-stroke diesel engine is the most mature prime mover available but may not meet the final weight goal.

\subsubsection{Rotary Diesel}

The rotary diesel offers some advantages that warrant further consideration (low weight and volume). We feel it is possible that an engine could be developed at the lower power ranges that could meet the weight goals required. The developmental barriers will be similar to those of the 2-stroke diesel, with the added concern of poor fuel economy. In our opinion, this engine makes sense only under conditions where the fuel economy is less important. 


\subsubsection{Otto Cycle}

The Otto cycle (spark ignited) engine is very mature for gasoline and could meet the weight requirement. If diesel fuel is burned, however, the engine will have reliability problems that would question its usefulness for expeditionary forces. If a reliable means of igniting diesel fuel in an SI engine is developed, this engine would possible satisfy the USMC needs. Fuel consumption is higher than the 2stroke diesel and meeting EPA requirements will be concern.

\subsubsection{Stirling Engine}

After much investigation and many innovative designs, the advantages of Stirling machines seem compelling only if a multifuel capability is needed, such as biofuel, nuclear, or solar energy. Portable power production appears worthwhile only for the low power range of $\sim 1 \mathrm{~kW}$ because the mediocre power density may be tolerable at this lower power range.

\subsection{Recommendations}

The following recommendations are made based on the results previously stated.

- This is a vital area that will require continued USMC attention. We recommend that the USMC further refine their needs and desires for generator sets for expeditionary forces.

- For larger sizes, we recommend that the USMC monitor the market on the commercial and military sides to determine if suitable generator sets will be available. In our opinion, it is highly likely that suitable (not perfect) gen-sets at this size range will be available in the 2010 timeframe without significant intervention (funding) from the USMC.

- The open Brayton cycles (gas turbine) is the best choice for the larger sizes if the diesel gen-sets being developed at DOD are not appropriate. Commercial products should be evaluated for their suitability. The open cycles should be developed first. If improved fuel economy becomes necessary, the closed Brayton cycle will be more attractive but the maturity level between the open and closed Brayton is large.

- USMC resources should be focussed on the smaller sizes $(1 \& 5 \mathrm{~kW})$ where the needs are greater and the risks must be minimized.

- The initial focus of any development should be on the areas of most importance (weight, volume, etc.). In other words, develop a small light engine first, then make it better by making it more efficient or quieter, etc.

- We recommend that for $1 \& 5 \mathrm{~kW}$, multiple options be pursued to minimize the risk and hopefully provide an optimum solution. We feel the best candidates are the Atkinson, Brayton (turbine), and 2stroke diesel cycles. Backup choices would be the rotary diesel and the SOFC.

- The backup choices should be watched to determine if they might overcome the shortfalls described in this report. UAV engine developments should be tracked for improvements in this technology.

- The Atkinson cycle is our recommendation as the most suitable engine to pursue even though it is the least mature of the three. Currently ORNL is working with the inventor to perform proof-of-principle 
tests for this engine, which should take several months to complete (October 2000). Pending a successful outcome, the overall suitability will be better known.

- The primary candidate engines (Atkinson, turbine, and 2-stroke diesel) should be further investigated and evaluated to identify the potential barriers of each and estimate the overall performance of a genset using each engine. Simulation packages at ORNL can be useful in this effort.

- Once the overall performance is estimated, the risks and costs associated with each engine can be determined and the decision to develop one or more potential solutions should be made.

It is our intent that this report will be used by the USMC to develop an engine that is suitable for expeditionary force gen-sets. This is a technically challenging area that will require attention from the USMC for the near future. 


\section{INTERNAL DISTRIBUTION}
1. J. B. Andriulli
2. T. R. Armstrong
3. J. C. Conklin
4. E. C. Fox
5. R. L. Graves
6. D. K. Irick

\author{
7. R. M. Schilling \\ 8-10. T. J. Theiss \\ 11. J. F. Thomas \\ 12. Central Research Library \\ 13. ORNL Laboratory Records-RC \\ 14. ORNL Laboratory Records-OSTI
}

\section{EXTERNAL DISTRIBUTION}

15. Maj. A. King Dixon III, USMC, Infantry Requirements Office, Requirements Division, 3300 Russell Road, Quantico, VA 22134

16-17. Capt. J. T. Judkins, USN, Marine Corps Warfighting Lab (C-52), 3255 Meyers Ave., Quantico, VA 22134-5096

18. S. N. Matthews, U. S. Army CECOM RD\&E Center, Power Generation Branch, AMSEL-RD-C2-AP-PG, 10108 Gridley Rd., Ft. Belvoir, VA 22060

19. Capt. W. M. Wando, Marine Corps Combat Development Command, Requirements Division (C445), 3300 Russell Rd., Quantico, VA 22134 


\section{Appendix 1}

Scores of Prime Movers

USMC Weight Factors 


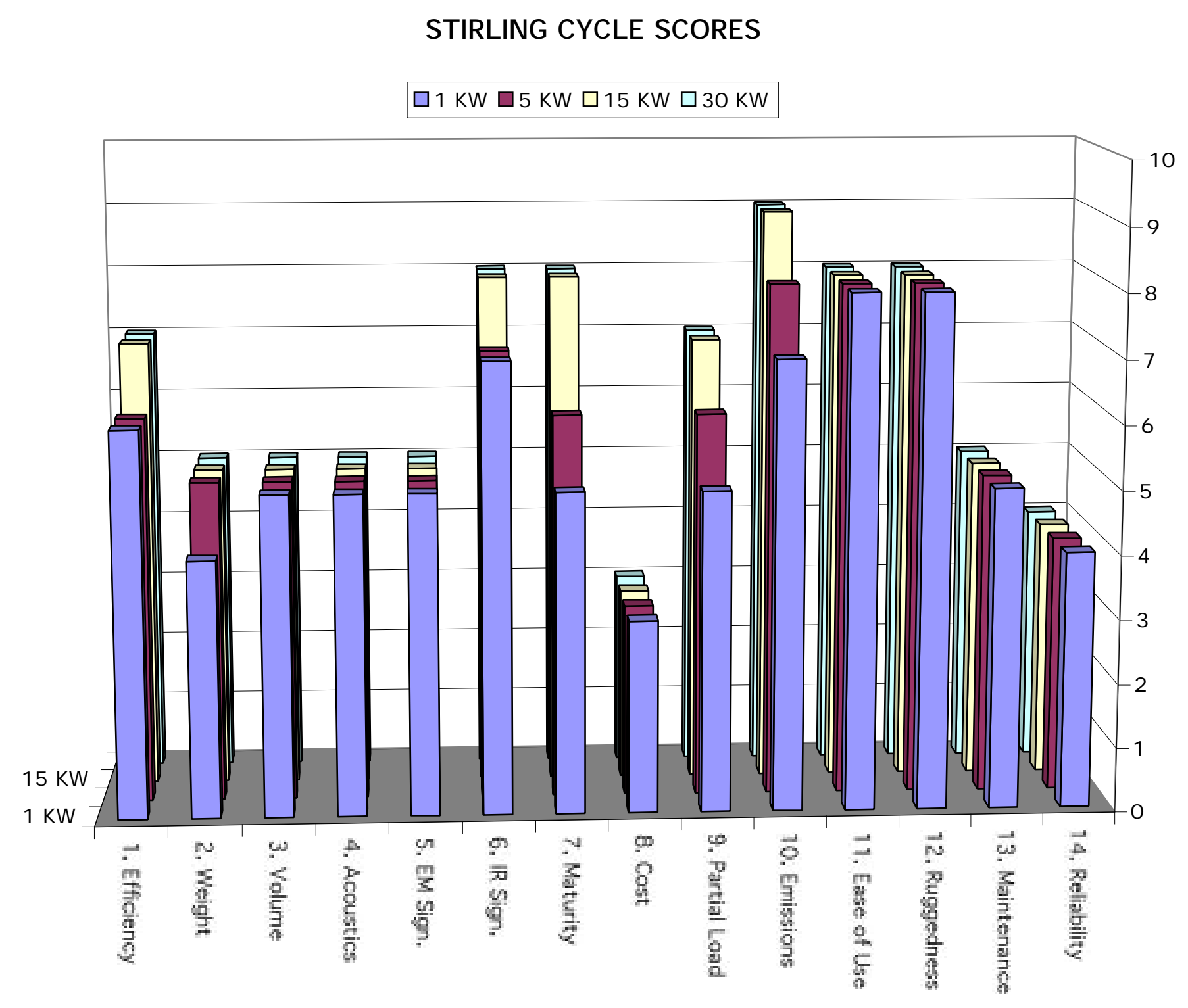


RANKINE CYCLE SCORES

$\square 1$ KW $\square 5$ KW $\square 15$ KW $\square 30$ KW

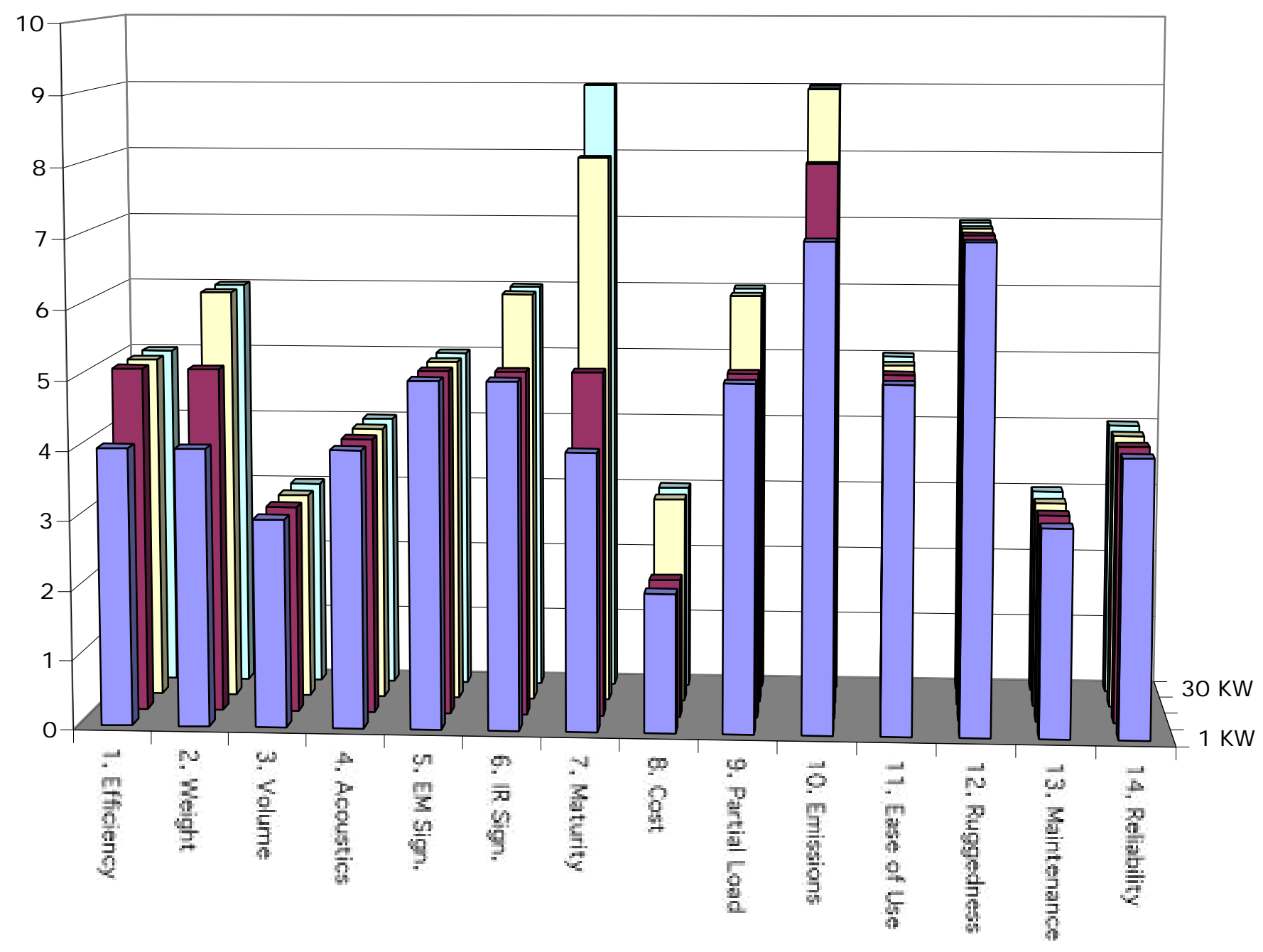


OPEN BRAYTON CYCLE SCORES

$\square 1 \mathrm{KW} \square 5 \mathrm{KW} \square 15 \mathrm{KW} \square 30 \mathrm{KW}$

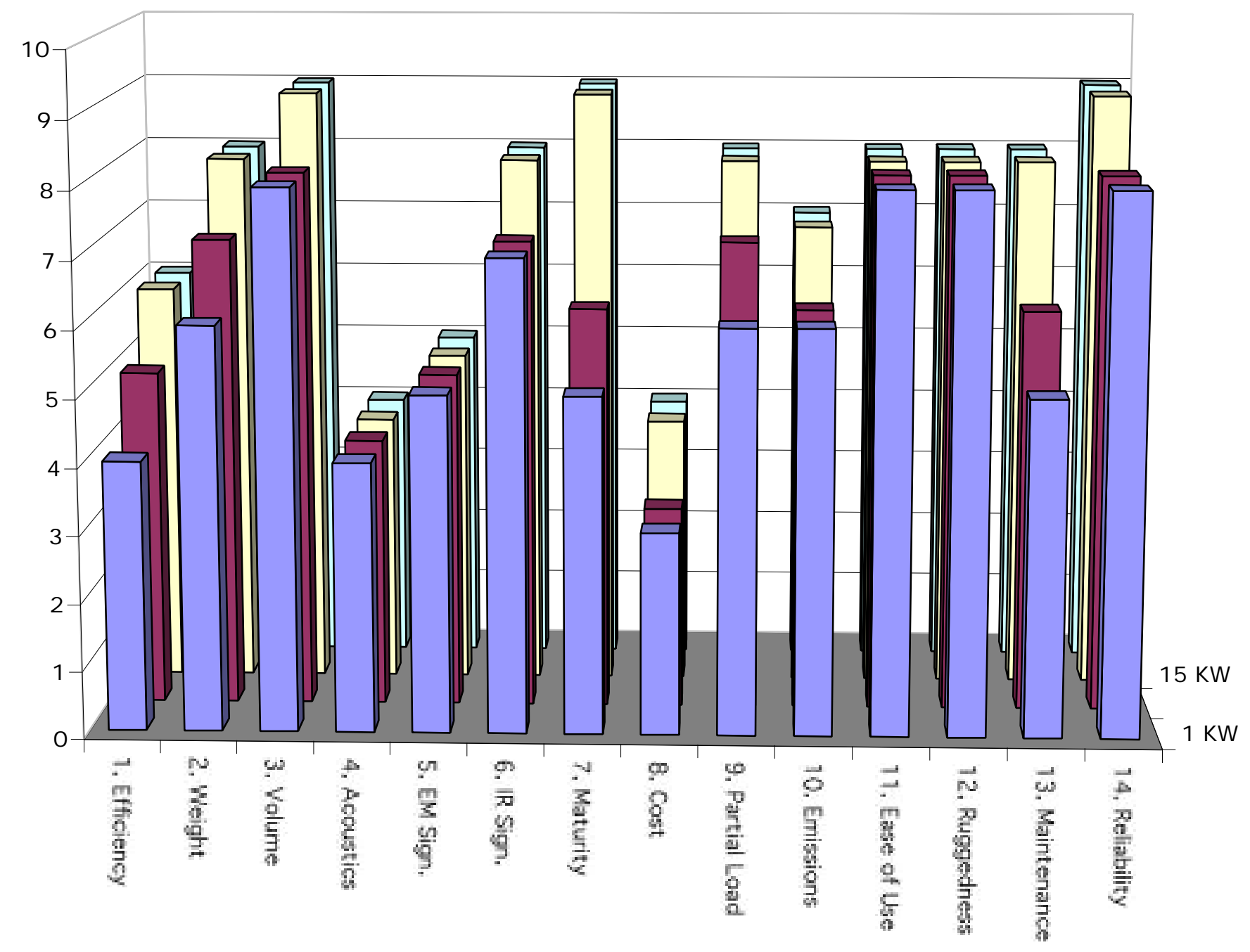


CLOSED BRAYTON CYCLE SCORES

$\square 1$ KW $\square 5$ KW $\square 15$ KW $\square 30$ KW

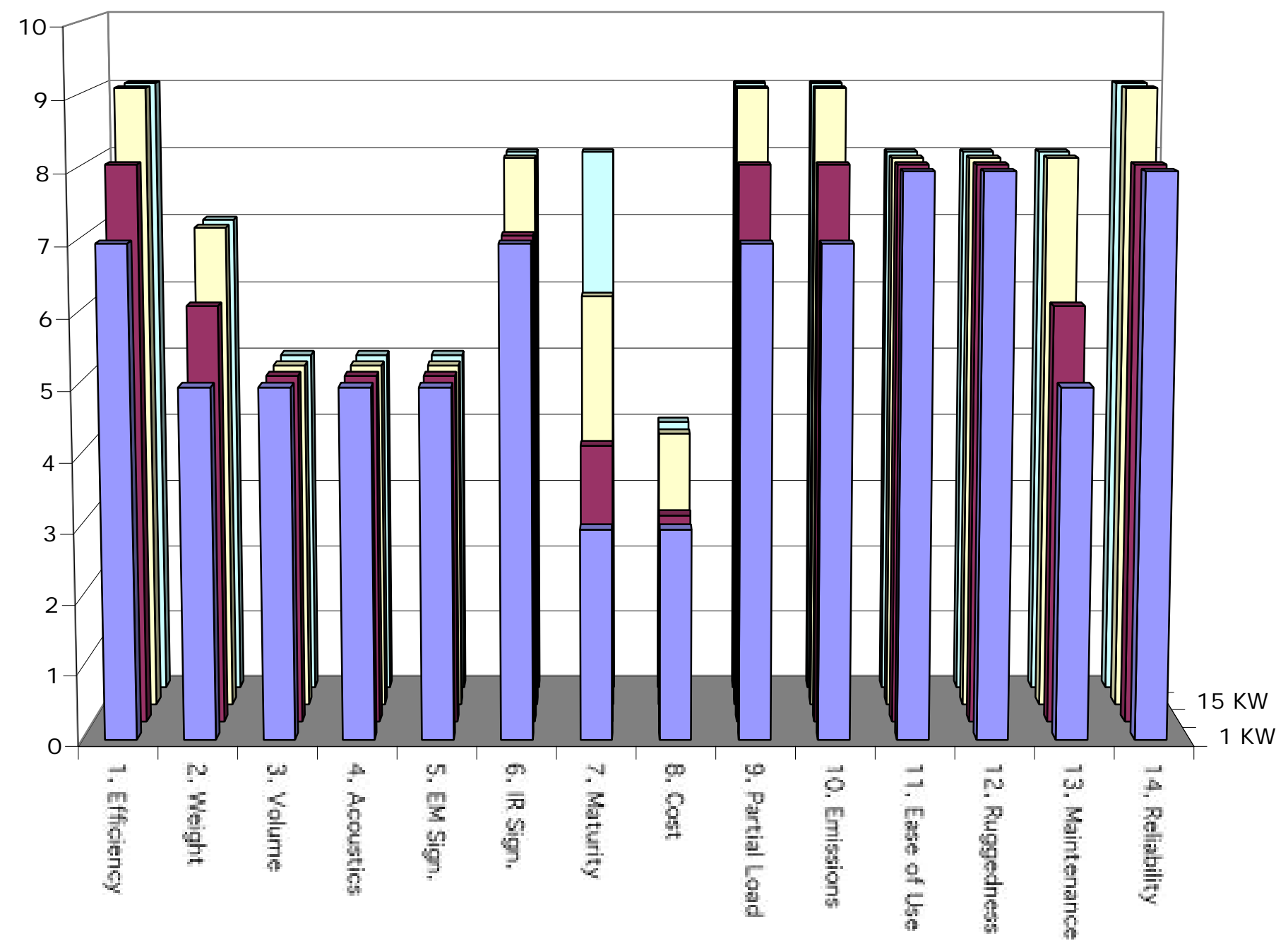


ACTIVE WORKING FLUID BRAYTON CYCLE SCORES

$\square 1 \mathrm{~kW} \square 5 \mathrm{~kW} \square 15 \mathrm{~kW} \square 30 \mathrm{~kW}$

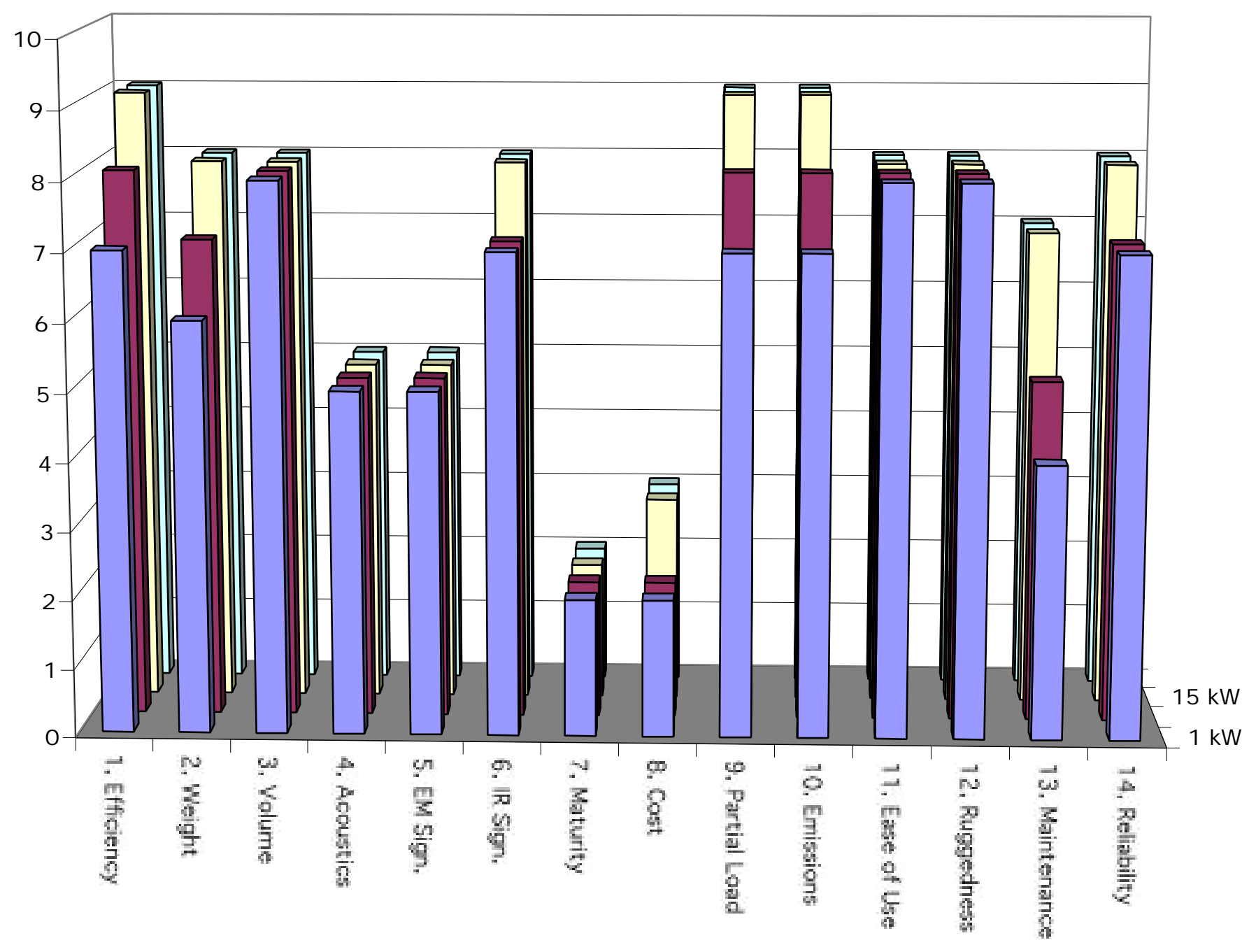


ATKINSON ENGINE SCORES

$\square 1$ kW $\square 5$ kW $\square 15$ kW $\square 30$ kW

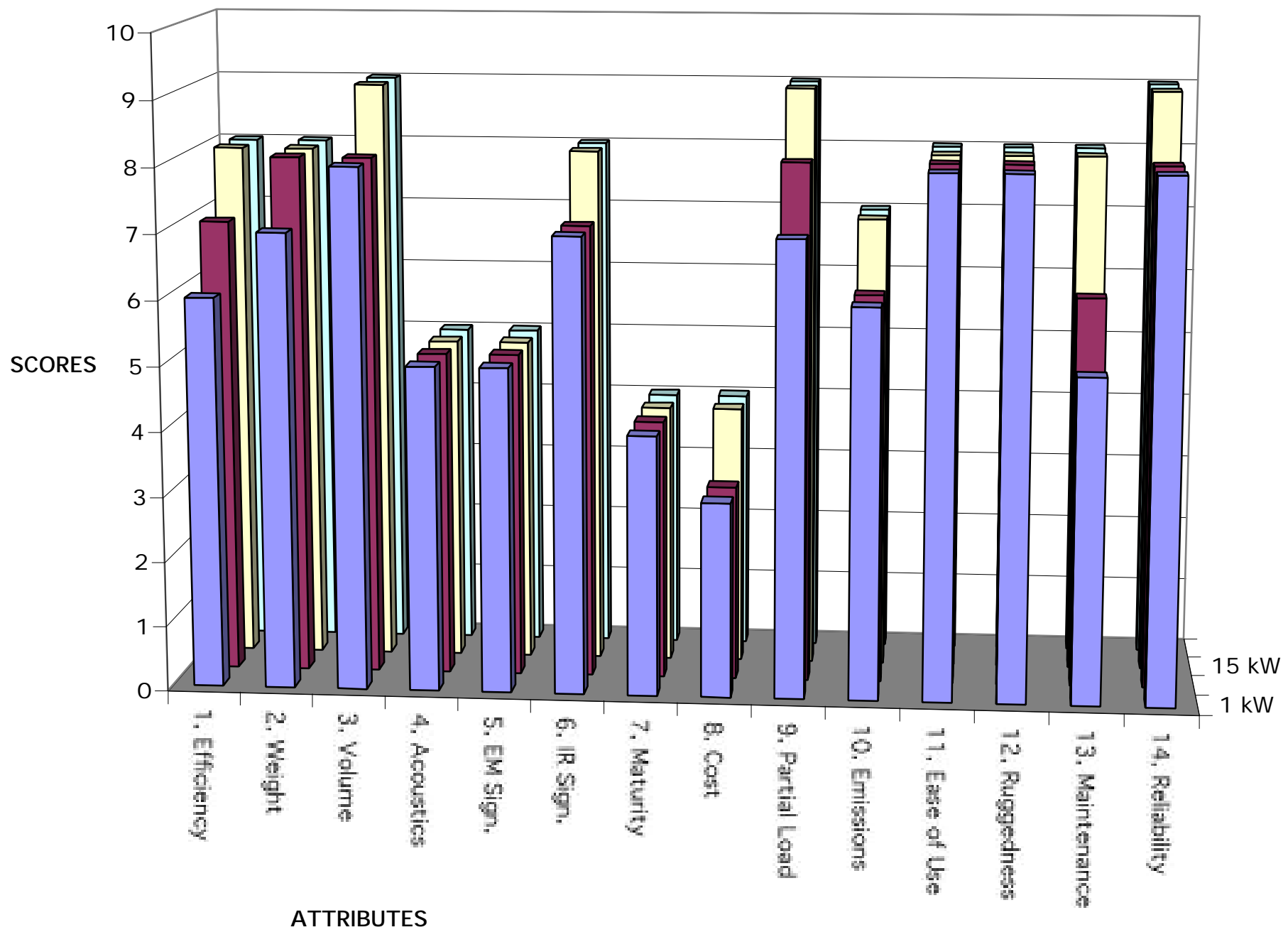


RECIPROCATING DIESEL ENGINE SCORES

$\square 1 \mathrm{KW} \square 5 \mathrm{KW} \square 15 \mathrm{KW} \square 30 \mathrm{KW}$

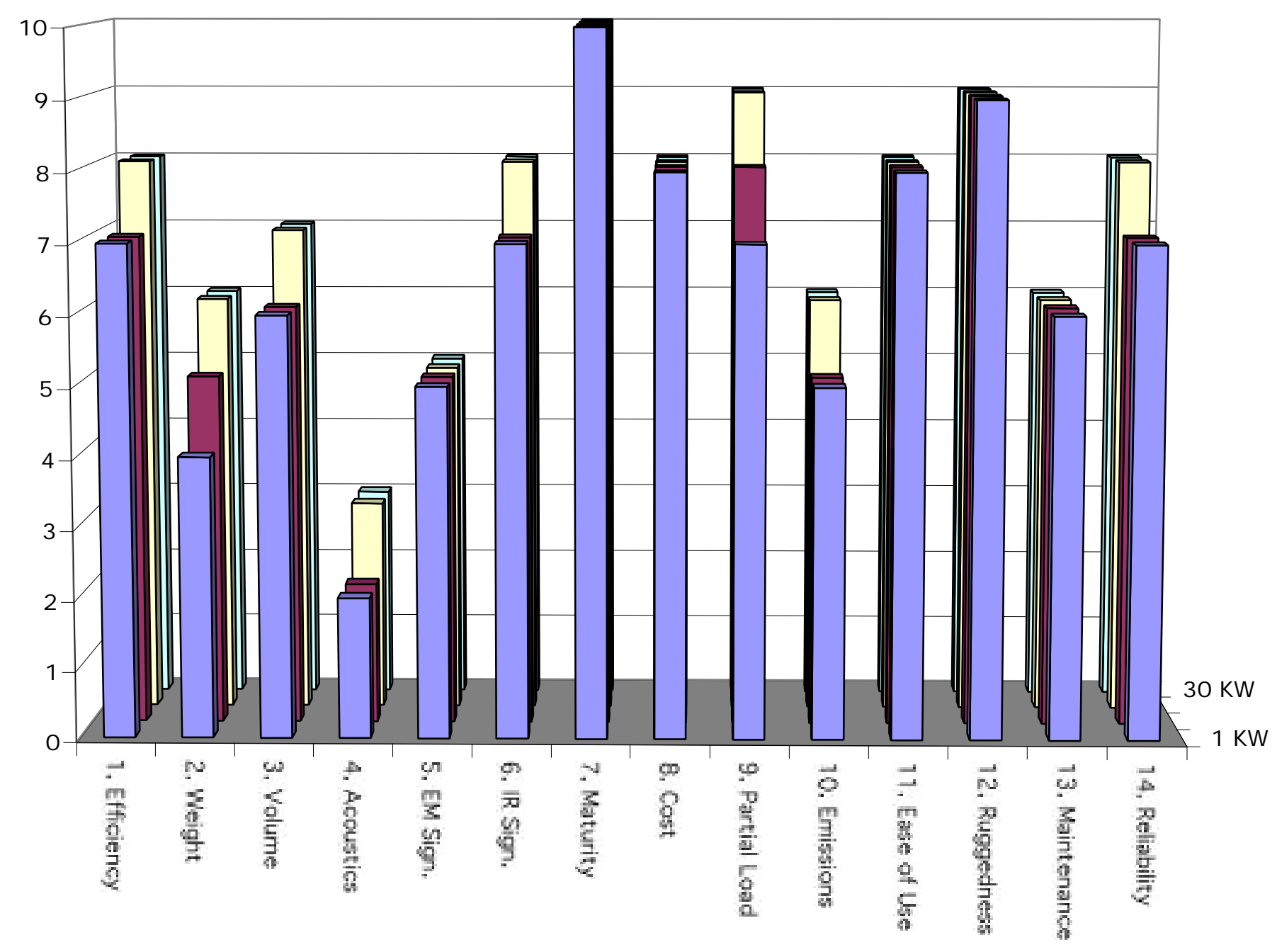


2 STROKE DIESEL

$\square 1$ kW $\square 5$ kW $\square 15$ kW $\square 30$ kW

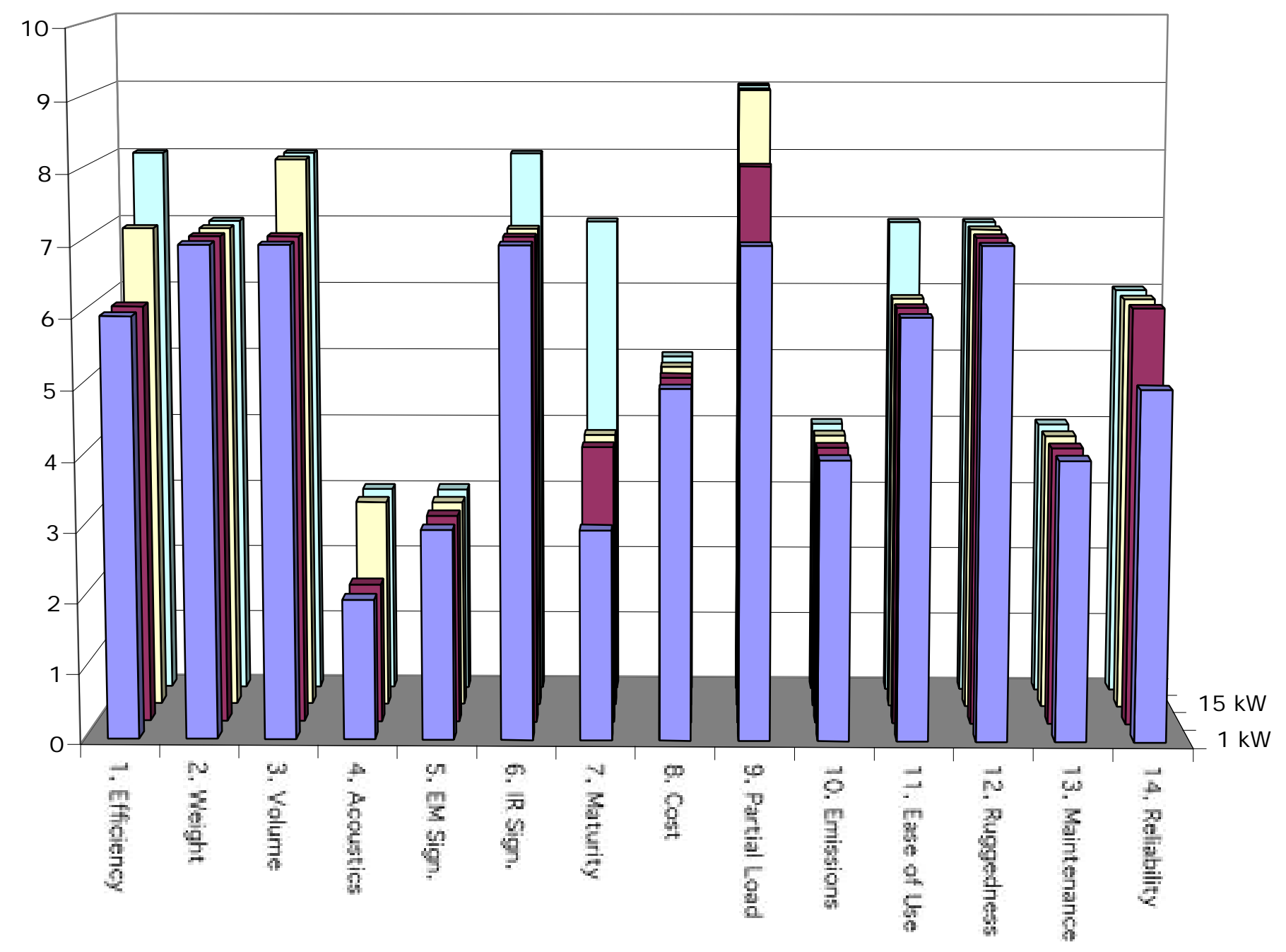


ROTARY DIESEL ENGINE SCORES

$\square 1$ KW $\square 5$ KW $\square 15$ KW $\square 30$ KW

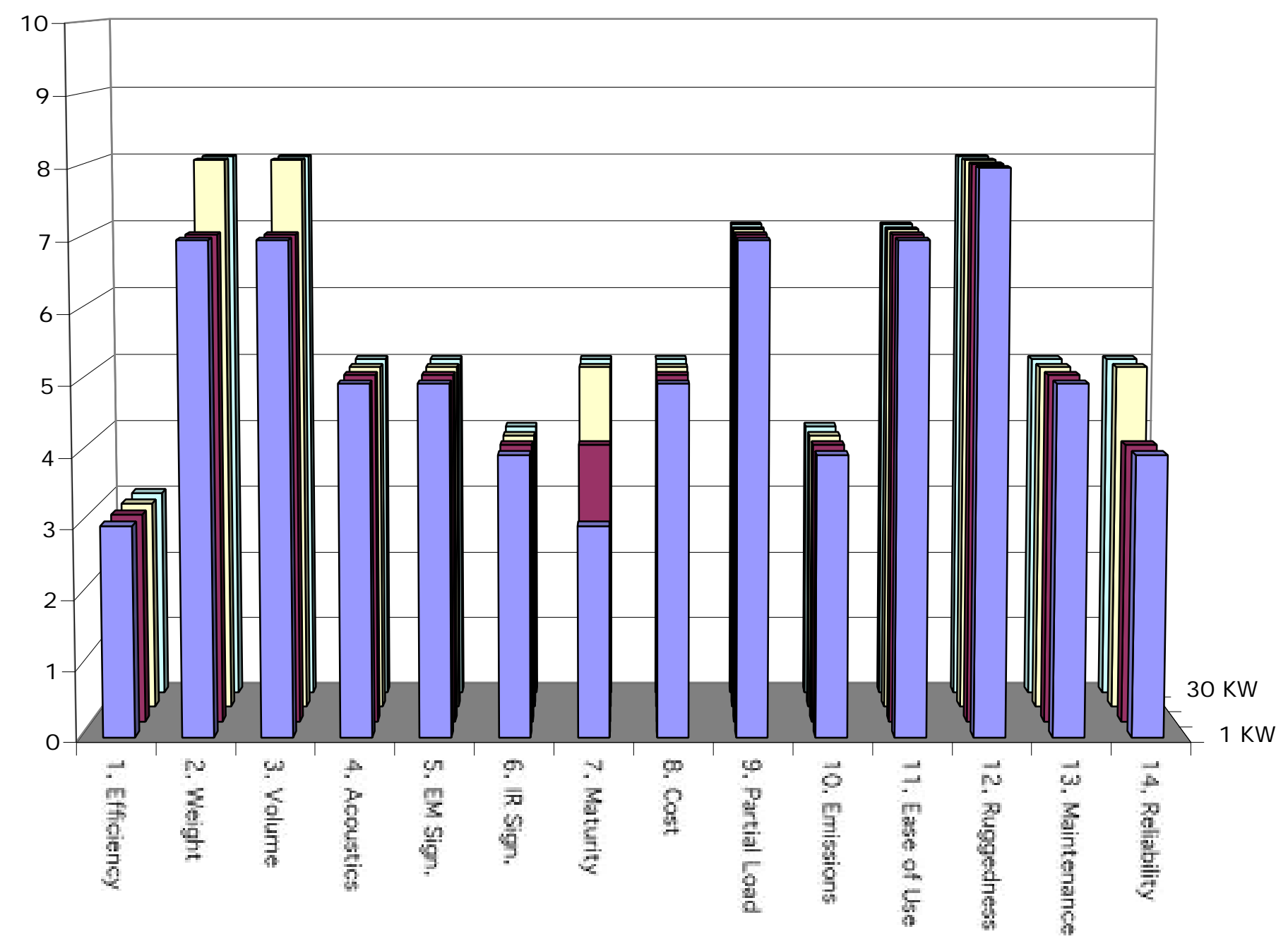


OTTO CYCLE SCORES

$\square 1 \mathrm{KW} \square 5 \mathrm{KW} \square 15 \mathrm{KW} \square 30 \mathrm{KW}$

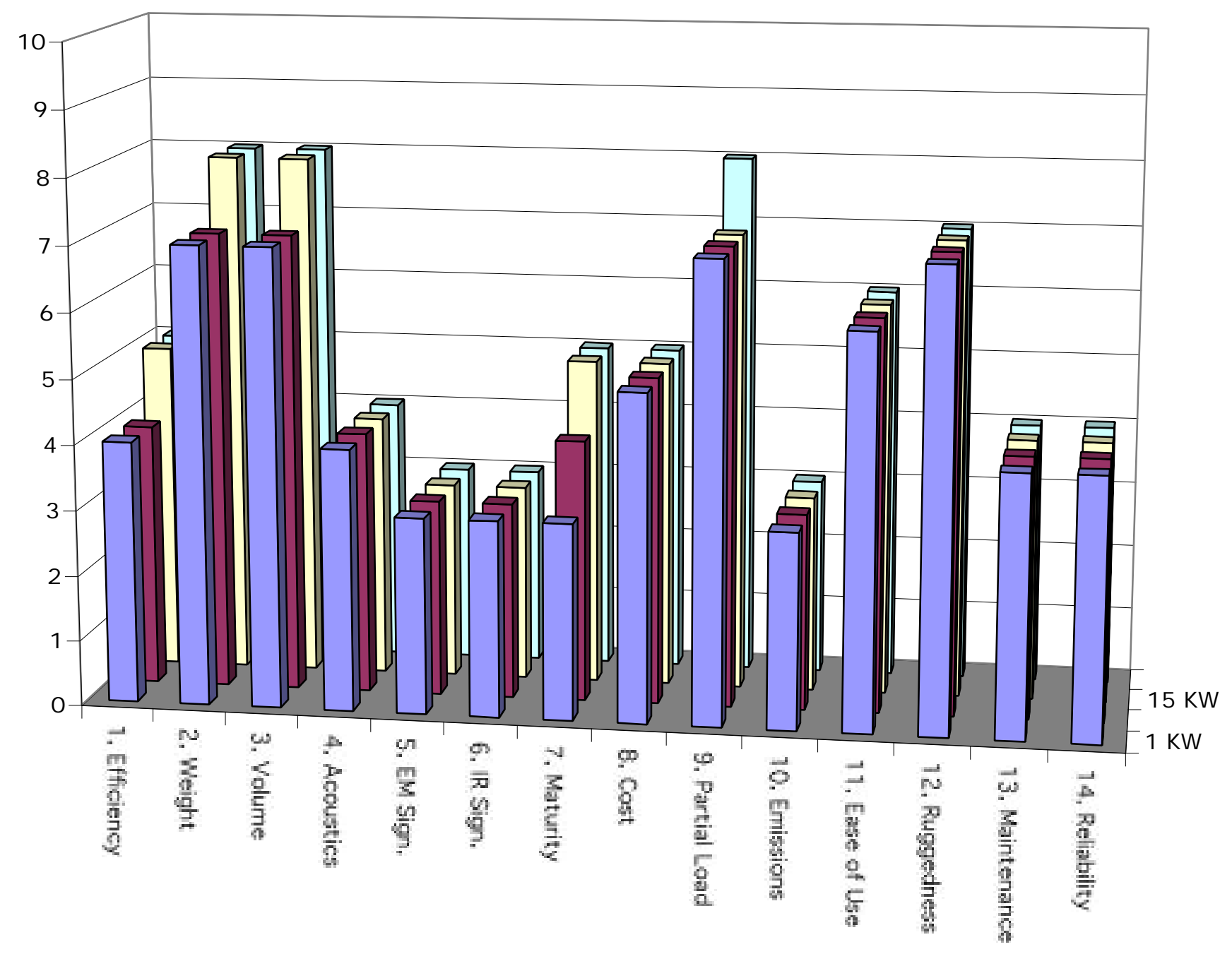


PEM FUEL CELL SCORES

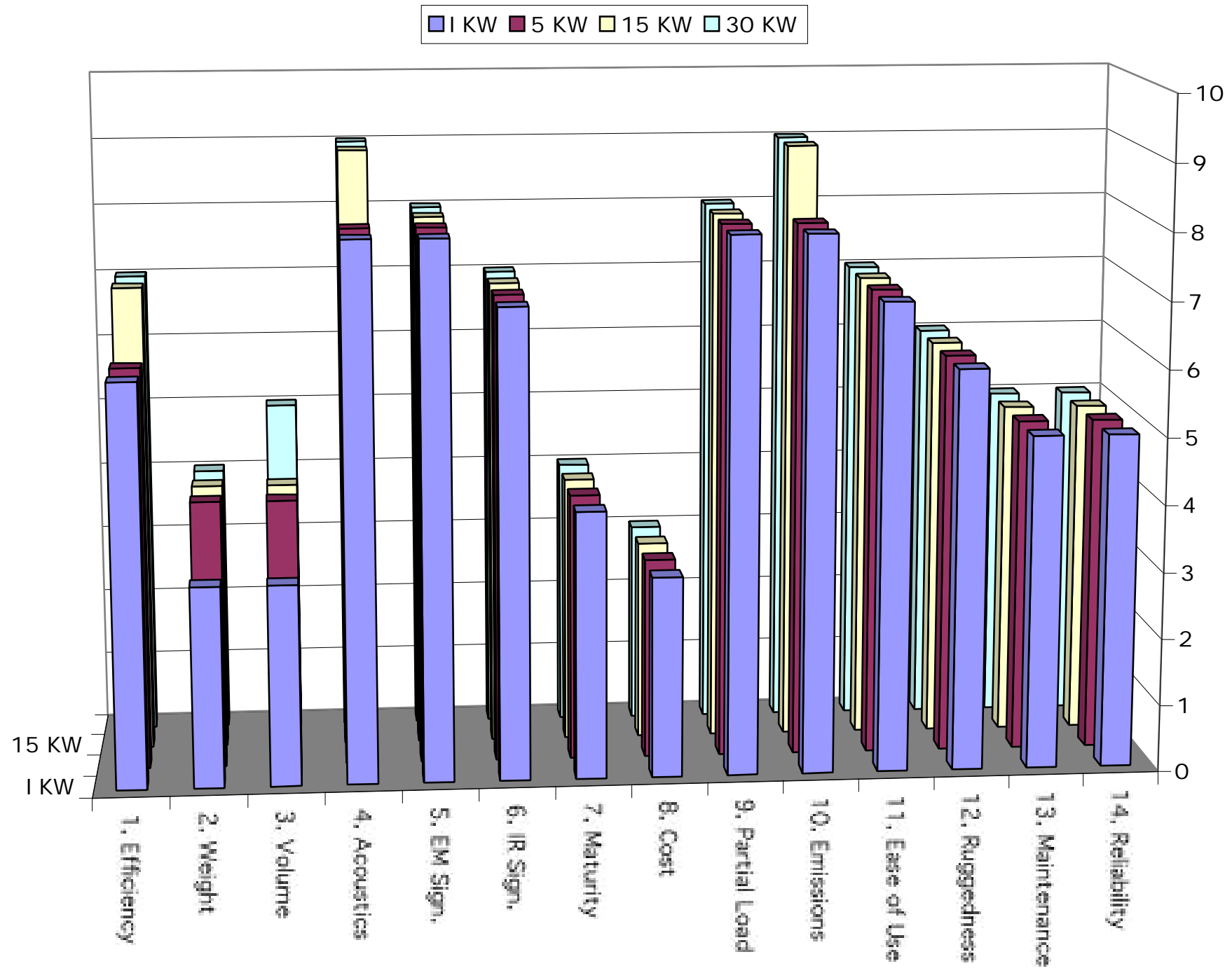


SOLID OXIDE FUEL CELL SCORES

$\square 1$ kW $\square 5$ kW $\square 15$ kW $\square 30$ kW

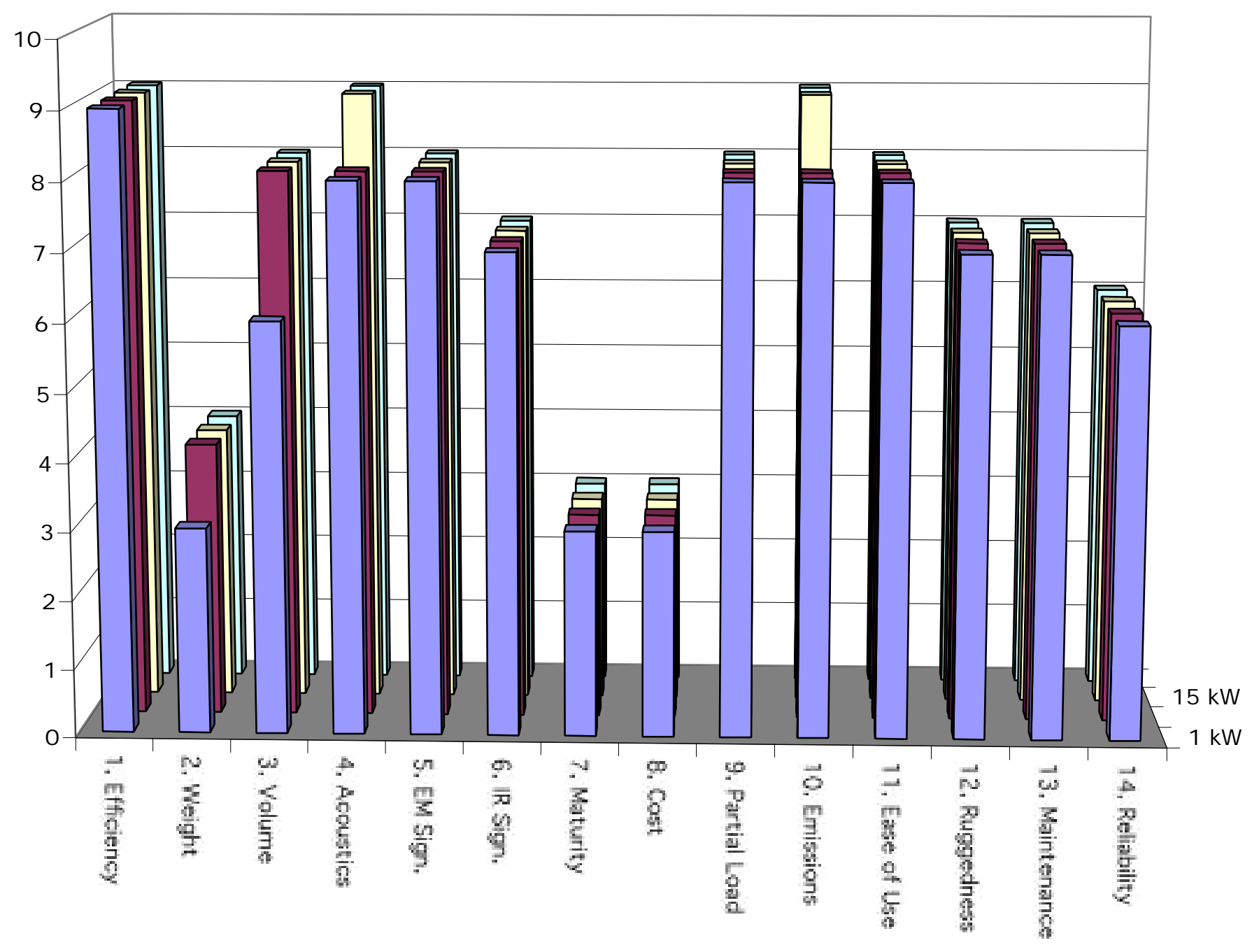


THERMOELECTRIC SCORES

$\square 1 \mathrm{KW} \square 5 \mathrm{KW} \square 15 \mathrm{KW} \square 30 \mathrm{KW}$

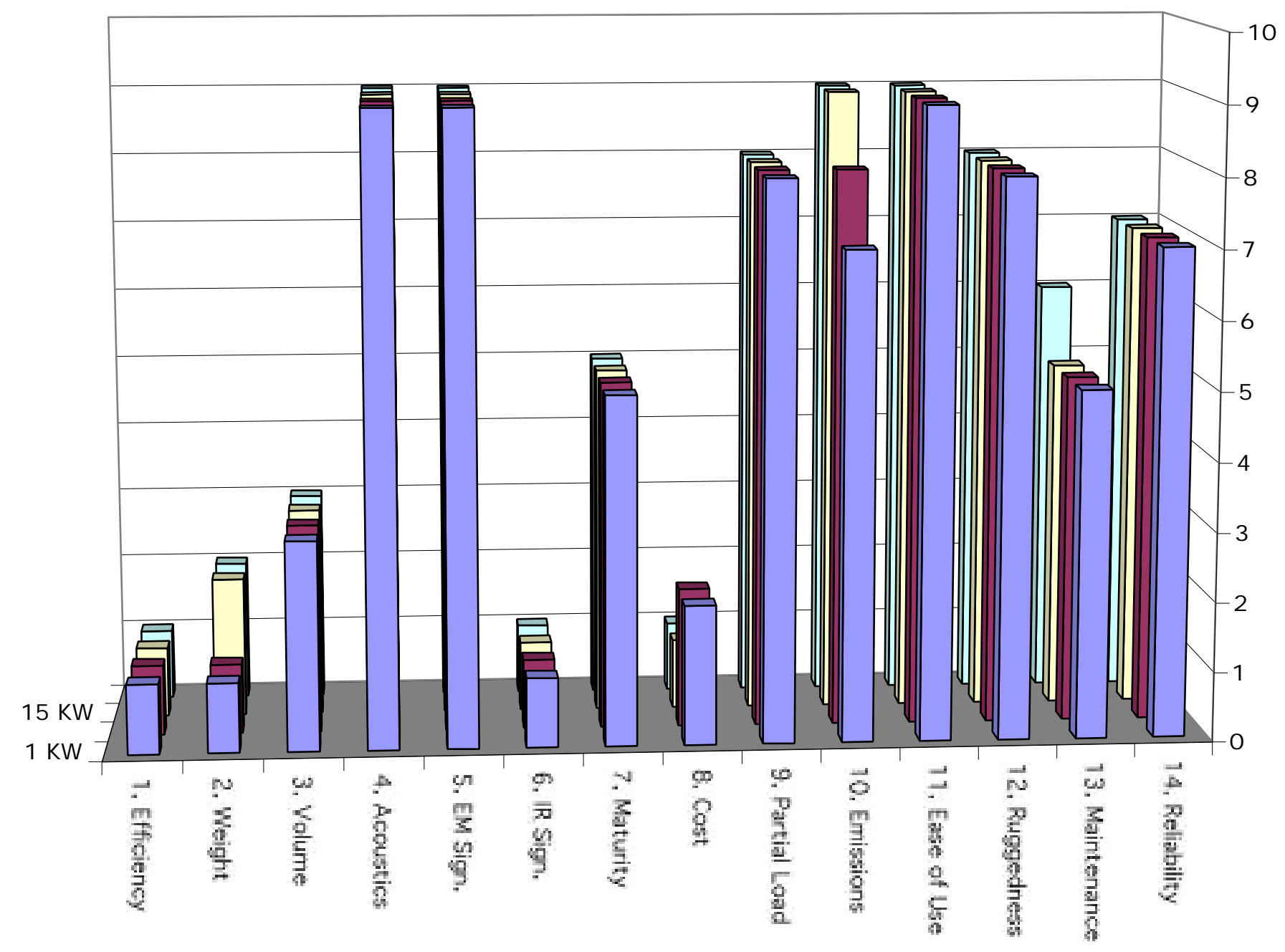


THERMOPHOTOVOLTAIC SCORES

$\square 1$ KW $\square 5$ KW $\square 15$ KW $\square 30$ KW

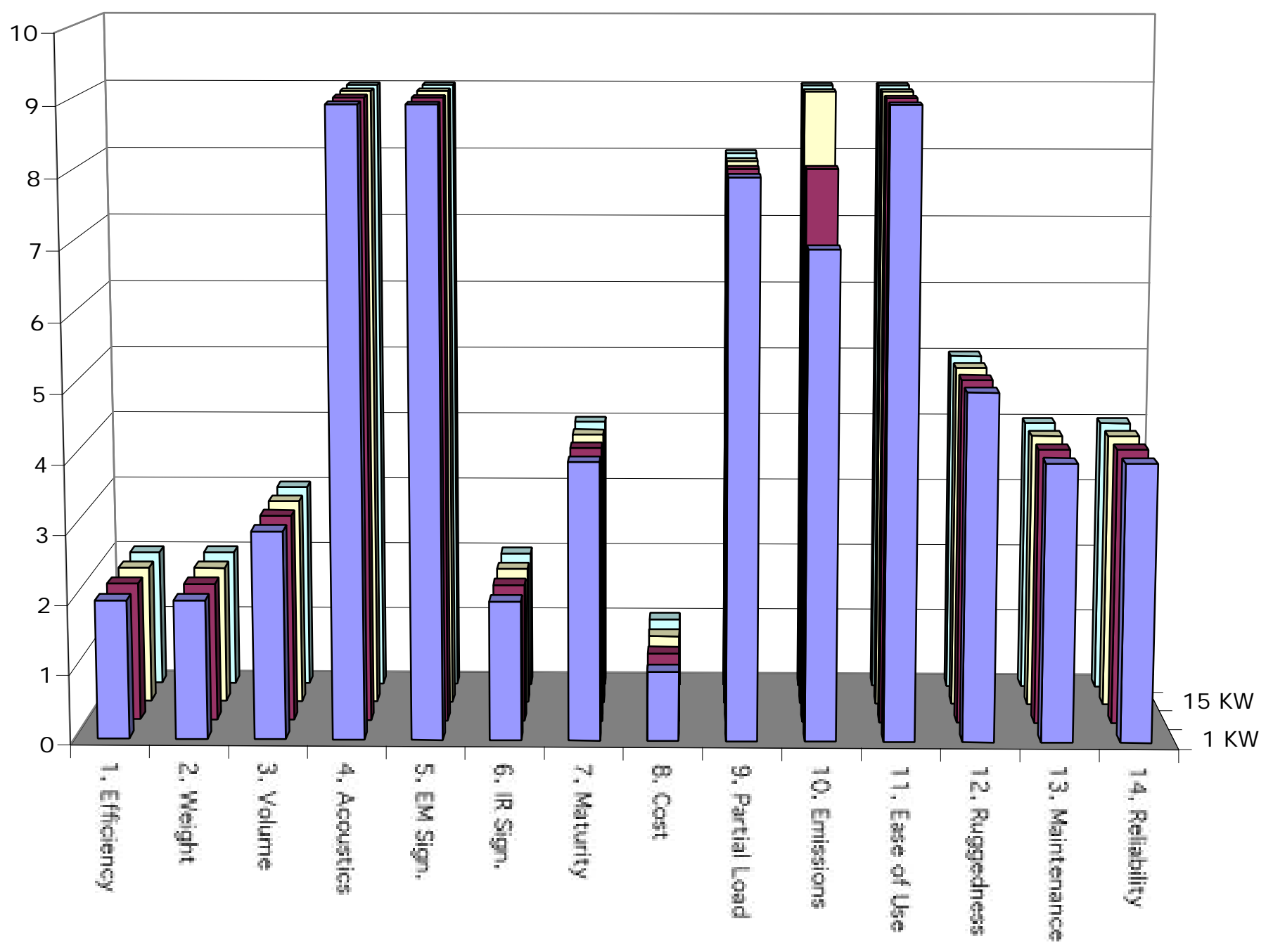


USMC WEIGHT FACTORS

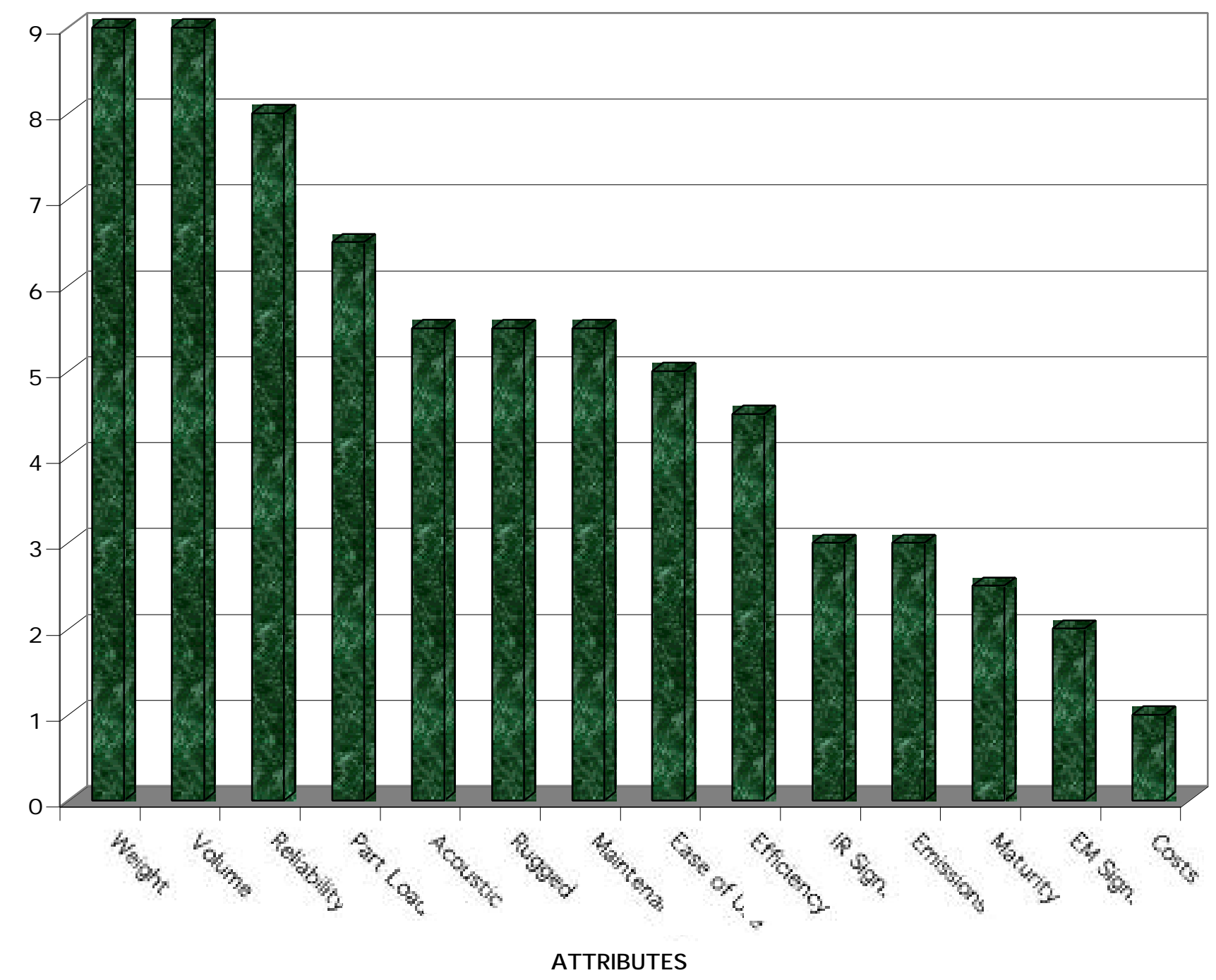

$\square$ Weight

QVolume

口 Reliability

口 Part Load

$\square$ Acoustic

a Rugged

$\square$ Maintenance

$\square$ Ease of Use

Efficiency

口IR Sign.

Emissions

口 Maturity

口EM Sign.

$\square$ Costs 


\title{
Appendix 2
}

\section{Final Weighted Scores of}

\author{
Prime Movers
}


FINAL SCORES FOR USMC PRIME MOVER

1 kW

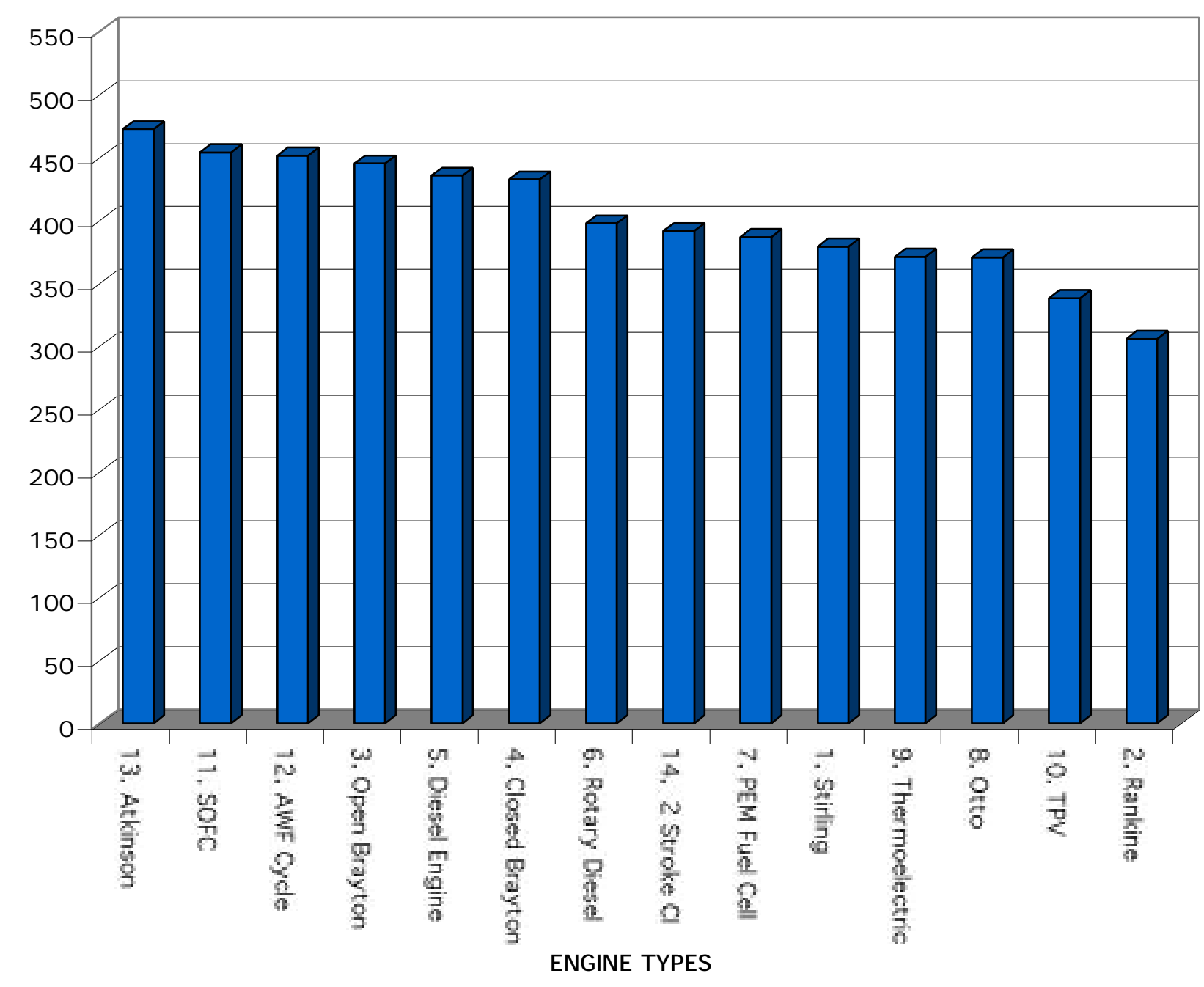

口Series1 
FINAL SCORES FOR USMC PRIME MOVERS

5 kW

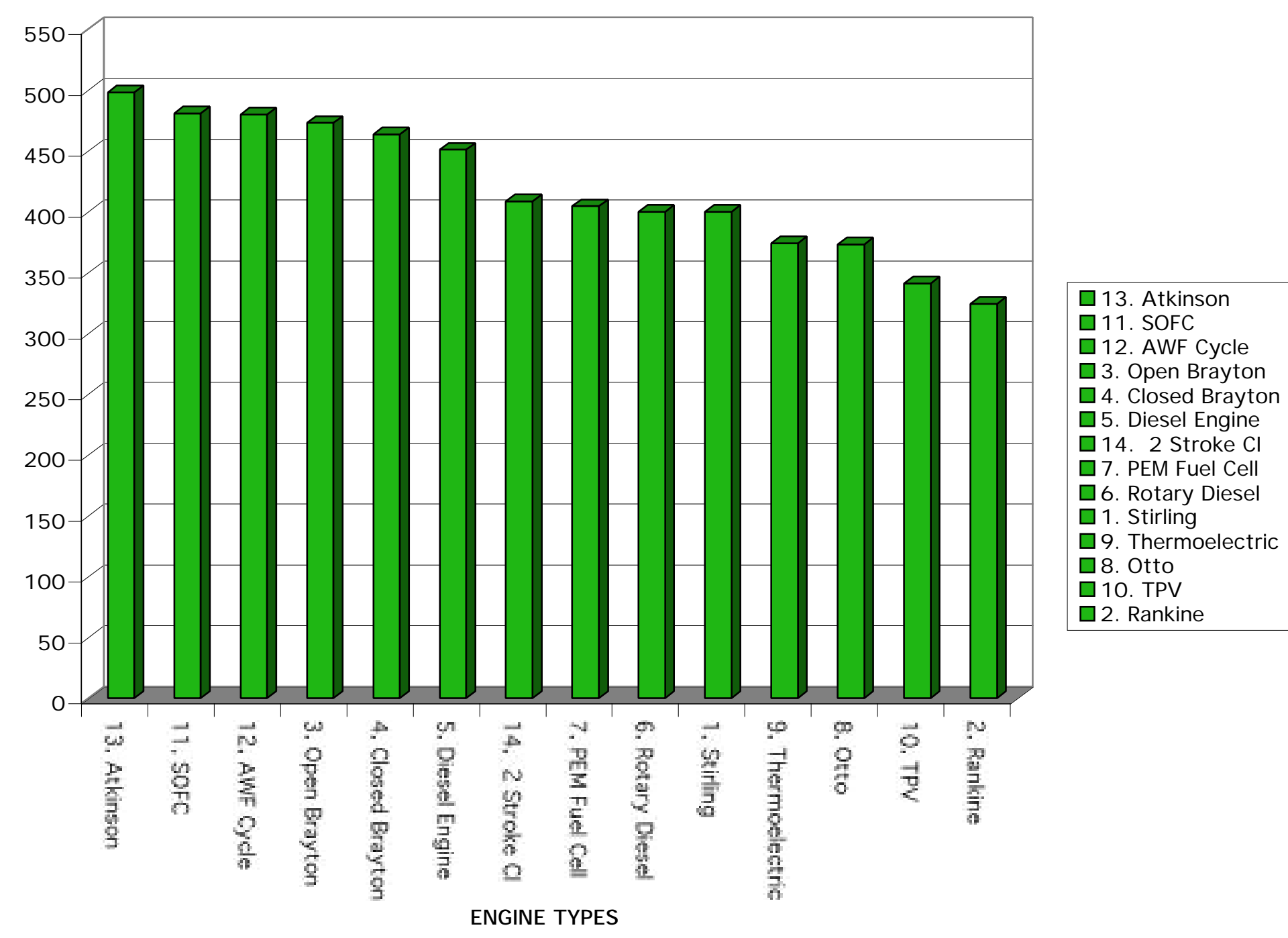


FINAL SCORES FOR USMC PRIME MOVER

15 kW

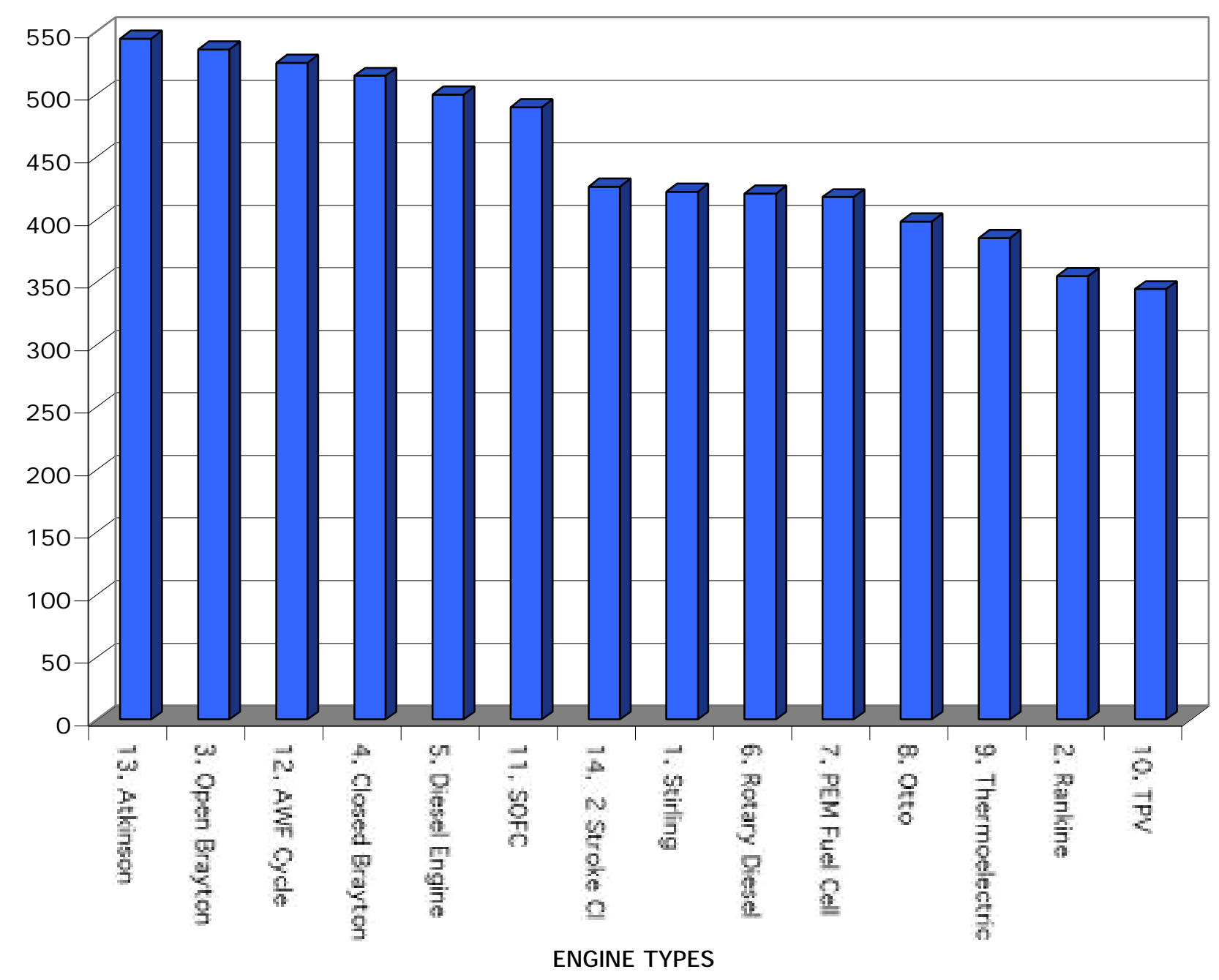

$\square$ Series 1 
FINAL SCORES FOR USMC PRIME MOVER

30 kW

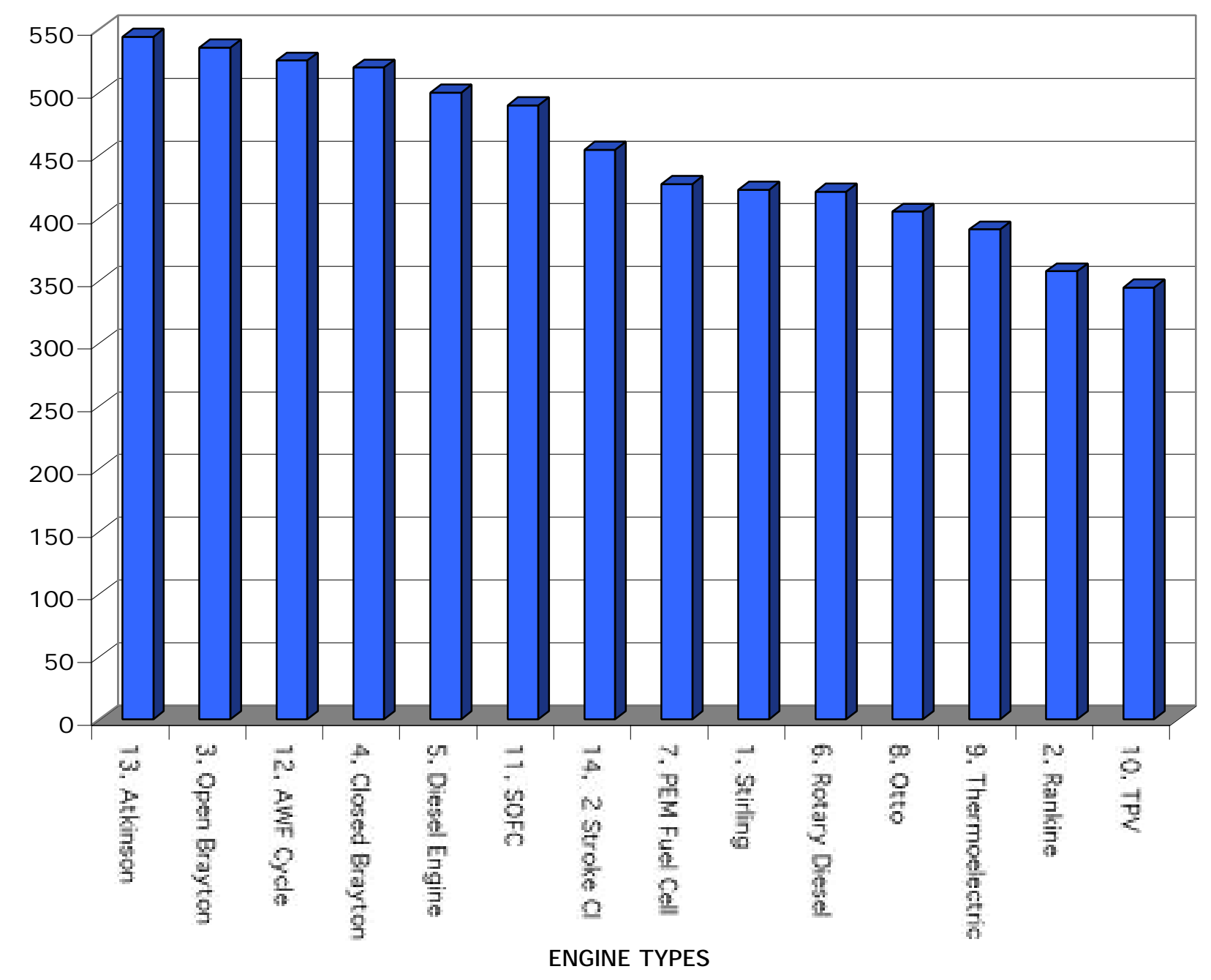

$\square$ Series1 
5 kW Overall Scores

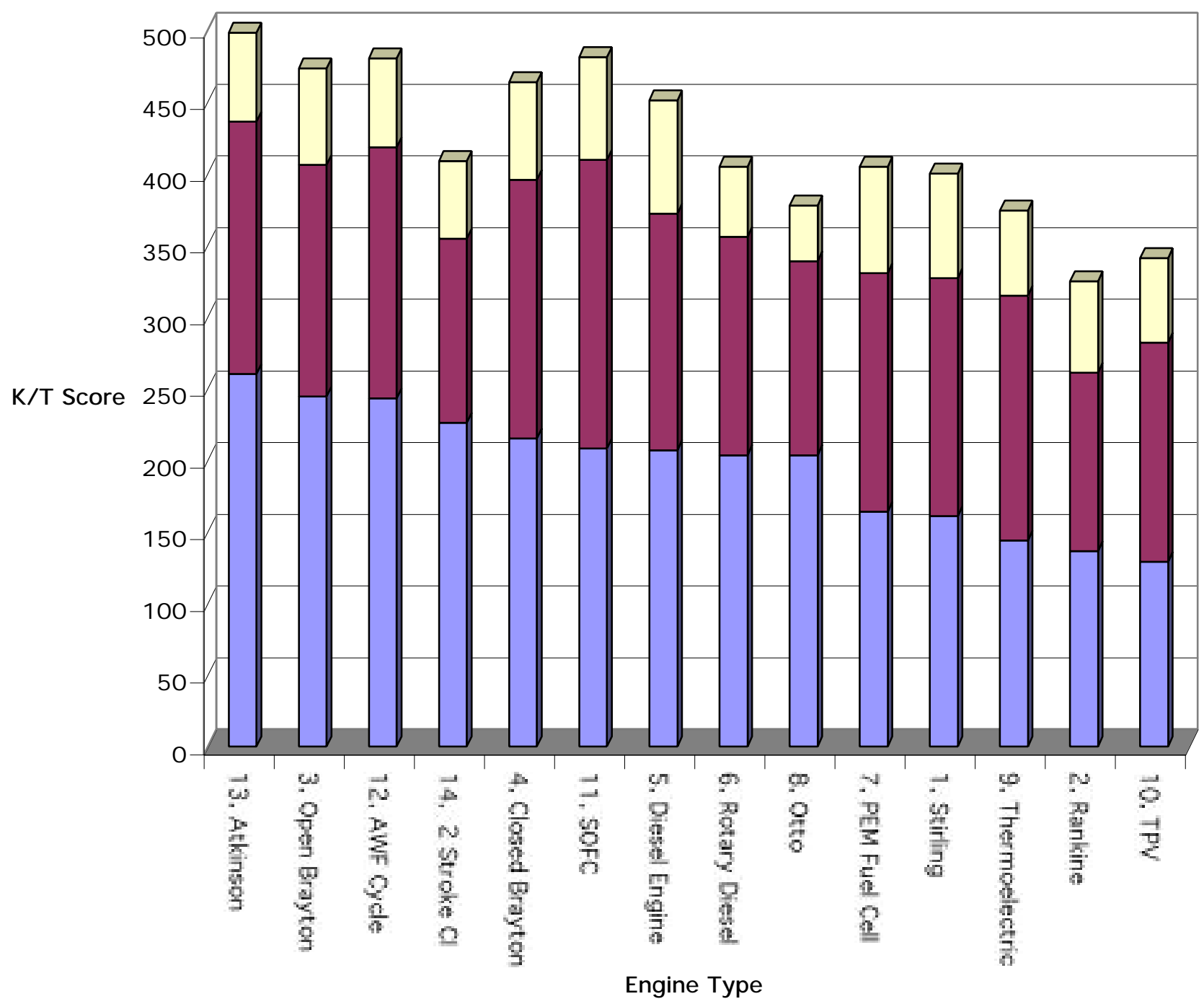

$\square$ Lower Importance

$\square$ Medium Importance

$\square$ High Importance 